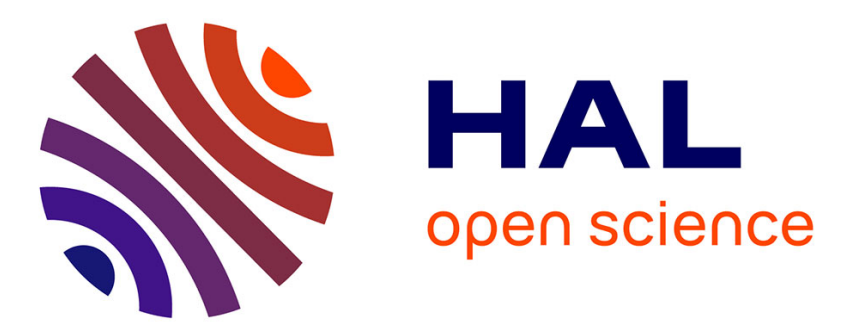

\title{
Impact of intra-daily SST variability on ENSO characteristics in a coupled model
}

Sébastien Masson, Pascal Terray, Gurvan Madec, Jing-Jia Luo, Toshio Yamagata, Keiko Takahashi

\section{- To cite this version:}

Sébastien Masson, Pascal Terray, Gurvan Madec, Jing-Jia Luo, Toshio Yamagata, et al.. Impact of intra-daily SST variability on ENSO characteristics in a coupled model. Climate Dynamics, 2012, 39, pp.681-707. 10.1007/s00382-011-1247-2 . hal-01323617

\section{HAL Id: hal-01323617 https://hal.science/hal-01323617}

Submitted on 30 May 2016

HAL is a multi-disciplinary open access archive for the deposit and dissemination of scientific research documents, whether they are published or not. The documents may come from teaching and research institutions in France or abroad, or from public or private research centers.
L'archive ouverte pluridisciplinaire HAL, est destinée au dépôt et à la diffusion de documents scientifiques de niveau recherche, publiés ou non, émanant des établissements d'enseignement et de recherche français ou étrangers, des laboratoires publics ou privés. 
Impact of intra-daily SST variability on ENSO characteristics in a coupled model

Sébastien Masson ${ }^{1}$ a, Pascal Terray ${ }^{\mathrm{a}}$, Gurvan Madec $^{\mathrm{a}}$, Jing-Jia Luo ${ }^{\mathrm{b}}$, Toshio Yamagata ${ }^{\mathrm{c}}$ and Keiko Takahashi ${ }^{\text {b }}$

a) LOCEAN/IPSL, CNRS/IRD/UPMC/MNHN, Paris, France

b) Research Institute for Global Change, JAMSTEC, Yokohama, Japan

c) Dept. of Earth and Planetary Science, Graduate School of Science, Univ. of

Tokyo, Japan

Submitted to Climate Dynamics

March 2011

${ }^{1}$ Corresponding author address : Sébastien Masson, LOCEAN-IPSL, Université Pierre et Marie Curie, BP100 - 4 place Jussieu, 75252 Paris cedex 05, France.

E-mail : smasson@locean-ipsl.upmc.fr 


\begin{abstract}
This paper explores the impact of intra-daily Sea Surface Temperature (SST) variability on the tropical large-scale climate variability and differentiates it from the response of the system to the forcing of the solar diurnal cycle. Our methodology is based on a set of numerical experiments based on a fully global coupled ocean-atmosphere general circulation in which we alter (1) the frequency at which the atmosphere sees the SST variations and (2) the amplitude of the SST diurnal cycle.

Our results highlight the complexity of the scale interactions existing between the intra-daily and inter-annual variability of the tropical climate system. Neglecting the SST intra-daily variability results, in our CGCM, to a systematic decrease of $15 \%$ of El Niño - Southern Oscillation (ENSO) amplitude. Furthermore, ENSO frequency and skewness are also significantly modified and are in better agreement with observations when SST intra-daily variability is directly taken into account in the coupling interface of our CGCM. These significant modifications of the SST interannual variability are not associated with any remarkable changes in the mean state or the seasonal variability. They can therefore not be explained by a rectification of the mean state as usually advocated in recent studies focusing on the diurnal cycle and its impact.

Furthermore, we demonstrate that SST high frequency coupling is systematically associated with a strengthening of the air-sea feedbacks involved in ENSO physics: SST / sea level pressure (or Bjerknes) feedback, zonal wind / heat content (or Wyrtki) feedback, but also negative surface heat flux feedbacks. In our model, nearly all these results (excepted for SST skewness) are independent of the amplitude of the SST diurnal cycle suggesting that the systematic deterioration of the air-sea coupling by a daily exchange of SST information is cascading toward the major mode of tropical variability, i.e. ENSO.
\end{abstract}

Keywords: diurnal cycle; coupled climate model; El Niño-Southern Oscillation; oceanatmosphere interactions 


\section{Introduction}

The el Niño-Southern Oscillation (ENSO) is one of the major modes of climate variability with critical environmental and economic impacts in the tropics, but also at mid-latitudes (McPhaden et al., 2006). Successive Coupled ocean-atmosphere General Circulation Model (CGCM) inter-comparisons show a clear improvement of simulation of ENSO within the last decade (Delecluse et al., 1998; Davey et al., 2002; AchutaRao and Sperber, 2002; Achutarao and Sperber, 2006). ENSO frequency, amplitude and spatial pattern are often better represented in current CGCMs. ENSO prediction skills of some CGCMs have been extended to more than one year (Luo et al., 2005a; Luo et al., 2008) and the best models even correctly represent higher order statistical moments like the positive skewness of eastern Pacific Sea Surface Temperature (SST) associated with ENSO (Wittenberg et al., 2006).

However, even the best current CGCMs (Wittenberg et al., 2006; Guilyardi et al., 2009) still suffer from difficulties in representing basic characteristics of ENSO such as its phase locking to the seasonal cycle. Moreover, the physical processes determining onset, strength and termination of ENSO events are still unsolved issues in seasonal prediction (Jin et al., 2008). Numerous studies explored the causes of these CGCM failures and looked for solutions (Manganello and Huang, 2009). Major systematic biases in the Pacific mean state and its annual cycle, such as the too strong zonal equatorial wind stress, the double InterTropical Convergence Zone (ITCZ) problem (Lin, 2007) or the Pacific equatorial cold tongue (Luo et al. 2005b, Reichler and Kim, 2008) have been suggested as key-factors for explaining errors in simulated ENSO (Guilyardi, 2006; Jin et al., 2008). However, for some coupled models, reducing one of these biases has no significant impact on ENSO simulation (Jochum et al., 2008). In addition, the impossibility to conclude anything about ENSO characteristics in Intergovernemental Panel on Climate Change fourth Assessment Report (IPCC AR4) experiments that exhibit significant and similar changes of their mean state under global warming (Collins et al., 2010) suggests that other pathways must be explored in order to improve CGCMs.

The role of air-sea interactions has been recently examined by means of different techniques (e.g., metrics for complex air-sea coupling processes and intermediate complexity models etc.) in order to improve our understanding of the physical feedbacks embedded in ENSO. Several studies suggested, for example, that the atmosphere plays a dominant role on ENSO behaviour in current CGCMs (Guilyardi et al., 2004; Neale et al., 2008; Navarra et al. 2008; Watanabe et al., 2011). This hypothesis is further supported by recent studies underlying the importance of atmospheric feedbacks on ENSO (Jin et al., 2006; Lloyd et al., 2009; Guilyardi et al., 2009; Lloyd et al., 2010). Several publications have also highlighted the role of ocean parameters on simulated ENSO characteristics (Meehl et al., 2001a; Yeh et al., 2010; Belmadani et al., 2010; Philip et al., 2010; Brown et al., 2011). However, the separation between ocean and atmosphere contributions to a coupled phenomenon such as ENSO is often difficult, if not impossible.

This paper aims to complete the previous explorations of the processes controlling ENSO in numerical simulations through an original perspective focusing on the role of "intra-daily" SST variability and scale interactions (Meehl et al., 2001b). The impact of the diurnal cycle on climate variability at longer time scales and how a proper representation of this cycle may help to reduce some of the CGCM biases have been recently been picked up from the long list 
of potential important upscaling processes and brought to the forefront (Danabasoglu et al., 2006; Bernie et al., 2008; Ham et al., 2010).

The pathways by which the diurnal cycle may impact longer time scales may be roughly classified in two categories (i) the atmospheric contribution, mostly represented by the role of the solar cycle in the air-sea coupling, and (ii) the oceanic contribution, which corresponds to the response of the coupled system to the SST diurnal cycle.

As an illustration, Danabasoglu et al. (2006) mainly focused on the atmospheric contribution. The introduction of the solar diurnal cycle significantly improves their CGCM mean state $\left(1^{\circ} \mathrm{C}\right.$ warming of the equatorial Pacific SST) and Niño3.4 SST standard deviation (reduction of $-0.4^{\circ} \mathrm{C}$ ). In addition, their work suggests that (1) $90 \%$ of the SST warming is due to an amplification by large-scale air-sea coupling, and (2) the impact of diurnal variability on climate variability is mainly due to the rectification of the mean state of the coupled system by the presence of the solar cycle. Ham et al. (2010) reached similar conclusions using another CGCM.

Slingo et al. (2003) adopted a different approach by focusing on the impact of the oceanic diurnal cycle. They emphasized the importance of scale interactions between diurnal, intraseasonal and seasonal time scales with a potential up-scaling impact up to ENSO. This idea was carried on one step ahead by Bernie et al. (2005) as they demonstrated that an explicit representation of the SST diurnal cycle ends up with a significant increase of the intraseasonal SST variability. In a following study, Bernie et al. (2008) have shown, in a CGCM, that the Madden-Julian Oscillation (MJO) signal is more coherent and propagates further eastward toward the international date line, when the oceanic diurnal cycle is properly simulated. These results were confirmed by Woolnough et al. (2007) whose forecasts were improved for active MJO phases over the Indian Ocean and western Pacific, by including an ocean mixed layer model in their forecasts system, which is able to represent the SST diurnal cycle.

All these previous studies stress the potential impact of the diurnal cycle on climate variability, but by different mechanisms and several points need to be highlighted here. First, the studies of Danabasoglu et al. (2006) and Ham et al. (2010) used ocean models with upper layers being too thick (vertical resolution of at least $10 \mathrm{~m}$ ) to correctly represent the oceanic response to the solar cycle forcing. Besides, Bernie et al. (2008) did not explore (or see) the impact of SST diurnal variability up to interannual time-scales as Danabasoglu et al. (2006) and Ham et al. (2010) did. There is thus no proper demonstration of an impact of oceanic response to the diurnal solar cycle on interannual variability. We also need to clarify the respective role of the solar cycle and SST high frequency variability on climate. According to Danabasoglu et al. (2006), the response of the coupled system to the introduction of the diurnal cycle in the coupling interface is mainly controlled by the solar cycle. Sensitivity experiments, based on a change of the coupling frequency from $24 \mathrm{~h}$ to $2 \mathrm{~h}$ (or $3 \mathrm{~h}$ ) for all the variables (Bernie et al., 2008; Ham et al., 2010), are thus inappropriate to quantify the specific impact of the SST high frequency variability in response to the solar cycle on climate variability.

In this study, we propose an original framework of sensitivity experiments in which we change only the SST coupling frequency (see the following section), in order to keep unchanged the contribution of the solar cycle to the climate system. Another goal of our work is to detail more precisely the nature of the high frequency SST variability, which matters for the longer time scales, especially ENSO variability. Is the impact on ENSO only related to the forcing of the solar cycle or to any other source of "intra-daily" variability? For example, the 
passage of an SST front associated with a tropical instability wave? To what extent an oceanic model with a standard vertical resolution of $10 \mathrm{~m}$ near the surface is able to represent the high frequency SST variability and its impacts on climate? All these questions will be addressed through the comparison of twin simulations with regular or very high vertical resolution in the ocean component of a state-of-the-art CGCM.

The paper is organized as follows: a brief review of the coupled model is given in section 2, along with a description of our sensitivity experiments and statistical tools used to assess the difference between these experiments. The diurnal and annual cycles of the Indo-Pacific climate as reproduced in the experiments are first analyzed in Section 3. In Section 4, we focus on the interannual variability of the Indo-Pacific region with a special attention to ENSO characteristics. Factors affecting El Niño variability are further explored in Section 5 through a quantitative analysis of the ENSO feedbacks in our different experiments. This is followed by discussion and conclusions in Section 6.

\section{Model, sensitivity experiments and statistical tools}

\subsection{Model description}

The results of this paper are based on a global CGCM called SINTEX-F2, which is an upgraded version of SINTEX-F1 (Luo et al., 2003; Masson et al., 2005; Luo et al., 2005b). SINTEX-F2 is close to the model used by Park et al. (2009) but with higher resolutions in the ocean and the atmosphere. This CGCM, developed in the frame of an European Union-Japan collaboration, is based on the ECHAM5.3 atmosphere model (Roeckner et al. 2003), a preparatory version of the NEMO v3.2 ocean model (Madec 2008) and the OASIS3 coupler (Valcke 2006).

The physics of the atmospheric model is close to the one used in SINTEX-F1 and we will not go into details in the present study. ECHAM5 includes the Tiedtke (1989) bulk mass flux formula for cumulus convection with modifications for penetrative convection according to Nordeng (1994), and the Morcrette et al. (1986) radiation code. See Luo et al. (2005a and b) for a more complete description of the physics of the atmosphere. The atmospheric grid has a relatively high horizontal resolution of about $1.1^{\circ}$ by $1.1^{\circ}$ (T106, same as in SINTEX-F1). A hybrid sigma-pressure vertical coordinate (31 levels instead of 19 for SINTEX-F1) is used with the highest resolution near the earth's surface (Roeckner et al., 2004).

The oceanic component is NEMO (Madec 2008) including LIM2 (Timmermann et al. 2005) for sea-ice model (SINTEX-F1 had no sea-ice model). We use the configuration known as "ORCA05" (Molines et al. 2006) which is a tri-polar global grid with a resolution of $0.5^{\circ}$ by $0.5^{\circ} \cos$ (latitude). The default vertical resolution is 31 levels with a layer thickness of about $10 \mathrm{~m}$ metre in the first 100 metres. In this study, we also use a very high vertical resolution of 301 levels ( $1 \mathrm{~m}$ near the surface) that was first used by Bernie et al. (2007). The next section, dedicated to the sensitivity experiments, details the use of these different oceanic resolutions. The set of physical parameters we used is based on Barnier et al. (2006) and Bernie et al. (2007). The ocean started from rest, initialized by a mean Levitus T-S field.

The coupling information, without any flux correction, is exchanged by means of the OASIS 3 coupler (Valcke, 2006) in its pseudo-parallel configuration. The next section gives more details about the coupling interface and coupling frequency. 


\subsection{Sensitivity experiments}

The main focus of this study is to quantify and differentiate the response of the coupled system to the intra-daily SST variability and the diurnal solar cycle. To achieve this goal, we keep a coupling frequency of $2 \mathrm{~h}$ for all fluxes (heat, freshwater and momentum) sent from the atmosphere to the ocean in all our sensitivity experiments. But, we send back the SST information to the atmosphere every 2 hours or 24 hours, depending on the experiment, in order to test the sensitivity of the system to the high frequency SST variability. Others oceanic data (surface currents, sea-ice variables) are always sent to the atmosphere every 2 hours. In other words, the oceanic component of the CGCM is always "seeing" the diurnal solar cycle in all the experiments. However, the atmosphere "sees" a new SST every 2 or 24 hours that corresponds to the mean SST value of the previous 2 or 24 hours. The atmosphere is always sending fluxes every 2 hours, but these fluxes are then computed according to a SST that is updated every $2 \mathrm{~h}$ or 24 hours depending on the experiment.

We also performed sensitivity tests on the amplitude of the SST intra-daily variability by modifying with the vertical resolution in the ocean (see previous subsection). The default configuration with 31 levels in the ocean has a strong thermal inertia of the surface layers that will strongly damp the SST response to the solar diurnal forcing. On the other hand, experiments with 301 oceanic levels are able to reproduce the strong SST intra-daily variability observed under clear sky and in low winds conditions (Bernie et al., 2008; Vialard et al., 2009). Thus, to test the robustness of our results and to further quantify the response to the SST coupling frequency, we have performed additional coupled experiments characterized by a strong (with 301 oceanic levels) or weak (with 31 oceanic levels) SST intra-daily variability in addition to the change of the SST coupling frequency.

In summary, we performed 4 experiments that combine the sensitivity tests to the SST coupling frequency ( $2 \mathrm{~h}$ or $24 \mathrm{~h}$ with experiment names starting by " $2 \mathrm{~h}$ " or " $24 \mathrm{~h}$ ") and to the oceanic vertical resolution (31 or 301 levels with experiment names ending by " 31 " or "301"). The computational cost of the 301 levels experiments forced us to reduce the length of these experiments to 75 years whereas 31 levels experiments where run for 110 years. In all cases, the first 10 years of the simulations have been removed from our analyses. Table 1 summarizes the specifications of the 4 sensitivity experiments used here.

\subsection{Statistical tools}

Since the focus of this study is on the interannual variability, we filtered out any long-term change or multi-decadal variability in both, observed and simulated monthly time series, by using the Seasonal-Trend decomposition procedure based on Loess (Locally weighted Scatterplot Smoothing), usually know as STL, which breaks down the series into a trend, a seasonal signal, and a residual (or noise) component (Cleveland et al., 1990). This procedure is particularly useful for extracting the interannual signal from non-stationary and noisy climate datasets (Morissey 1990, Terray, 2010). However, all calculations described in Sections 4 and 5 were performed with and without the STL procedure and the main results were similar. Indeed, the STL filtering hardly changes the main patterns of variability, but slightly increases the fraction of variance explained by these interannual modes (not shown).

Spectral analysis based on a "classic" Fast Fourier Transform algorithm on overlapping segments has been used for depicting the timescales involved in the interannual variability of the observed and simulated fields (Welch, 1967). In order to determine the significant 
changes in ENSO frequency between the different experiments and the observations, the $99 \%$ confidence interval relative to the spectrum estimated from observations has been plotted rather than the $99 \%$ confidence level based on a red or white noise continuum. To set these point-wise confidence limits on the spectral estimates $\mathrm{f}(\mathrm{w})$, where $\mathrm{w}$ is a Fourier frequency, we have to take $c_{1}$ and $c_{2}$ to be the lower and upper 0.005 -critical values of the $\chi^{2}$ value corresponding to the degree of freedom $d f$ of the spectral estimate $\mathrm{f}(\mathrm{w})$ (i.e. $\operatorname{prob}\left(\chi^{2}<=\mathrm{c}_{1}\right)=$ $\left.\operatorname{prob}\left(\chi^{2}>\mathrm{c}_{2}\right)=0.005\right)$, and evaluate the lower (l) and upper (u) confidence limits as $\mathrm{l}=$ $d f . \mathrm{f}(\mathrm{w}) / \mathrm{c}_{2}$ and $\mathrm{u}=d f . \mathrm{f}(\mathrm{w}) / \mathrm{c}_{2}$, respectively (von Storch and Zwiers, 1999).

Another important question is how to compare quantitatively two estimated spectra: $f_{1}(w)$ and $\mathrm{f}_{2}(\mathrm{w})$ with $d f_{1}$ and $d f_{2}$ degrees of freedom. To answer this question, spectral analysis theory suggests to examine the spectral ratios $\mathrm{R}(\mathrm{w})=\mathrm{f}_{1}(\mathrm{w}) / \mathrm{f}_{2}(\mathrm{w})$, which may be assumed to follow an F-distribution with numerator and denominator degrees of freedom $d f_{1}$ and $d f_{2}$, respectively. This result can be used to calculate point-wise confidence (or tolerance) intervals for the spectral ratios and will be used to test the hypothesis of a common spectrum of time series from two experiments in Section 4. For additional details on these spectral computations, see Diggle (1990).

Maximum Covariance Analysis (MCA, also called Singular Value Decomposition (SVD) in early papers) is used to quantify the strength of the various oceanic and atmospheric feedbacks. In the observations, the intensity of these feedbacks is usually assessed by the slope of linear regressions of various fields onto the Niño-3 SST and Niño-4 zonal wind stress anomalies, both regions being the maximum variability zone for the respective variables (Gill, 1980; Clarke, 1994). But in the models, as the shape and evolution of the simulated ENSO differ sometimes significantly from the observed ones, the MCA is undoubtedly a more refined method than a simple linear regression onto the rough average of SST (or zonal wind stress) anomalies in a fixed box such as Niño-3 or Niño-4.

MCA can be considered as a generalization of the Empirical Orthogonal Function (EOF) analysis (Bretherton et al., 1992). It aims at estimating the covariance matrix between two fields and at computing the SVD of this covariance matrix for defining pairs of spatial patterns, which describe a fraction of the total square covariance (SCF). In all MCA analyses presented here, the computations are based on temporal covariance matrices weighted by cosine of the latitude so that equal areas carry equal weights. The MCA results in spatial patterns and time series. The $k$ th Expansion Coefficient (EC) time series for each variable is obtained by projecting the original monthly interannual anomalies onto the $k$ th singular vector of the SVD of the covariance matrix. Using the ECs from the MCA, two types of regression maps can be generated: the $k$ th homogenous vector, which is the regression map between a given data field and its $k$ th $\mathrm{EC}$, and the $k$ th heterogeneous vector, which is the regression map between a given data field and the $k$ th $\mathrm{EC}$ of the other field. The $k$ th heterogeneous vector indicates how well the grid point anomalies of one field can be predicted from the $k$ th EC time series of the other field. Both types of regression maps are used extensively in Section 5, as they give precious information about the nature and strength of the ocean-atmosphere coupling in the different simulations.

The SCF is a first simple measure of the relative importance of each mode in the relationship between two fields. On the other hand, the correlation value $(r)$ between the $k$ th ECs of the two fields and the Normalized root-mean-square Covariance (NC), introduced by Zhang et al. (1998), indicate how strongly related the coupled patterns are.

Finally, higher statistical moments, such as skewness and kurtosis, provide also powerful tools for validating coupled models and testing non-linearity of the observed and modeled 
climate systems (Burger and Stephenson, 1999). In this study, we used unbiased moment estimate of skewness to measure the deviation of a distribution from symmetry and to diagnose non-linear processes. This statistic may be computed as

$$
\text { Skewness }=n \cdot \mathrm{M}_{3} /\left[(n-1)(n-2) \cdot \sigma^{3}\right]
$$

, where $\mathrm{M}_{3}$ is $\sum\left(\mathrm{x}_{\mathrm{i}^{-}} \overline{\mathrm{x}}\right)^{3}, \sigma^{3}$ is the unbiased estimate of standard deviation raised to the third power and $n$ is the number of observations.

\section{Mean state and seasonal variability}

In this section, we first present a quick validation of the mean state and seasonal cycle of the tropical climate in this new version of the SINTEX-F CGCM. Next, we will show that coupling the SST every 2 or 24 hours has no significant impact on either the mean state or the seasonal cycle, even in the 301 levels configuration of our CGCM.

\subsection{Validation of the coupled model}

Except for the SST diurnal cycle, all validations will be done with the $2 \mathrm{~h} 31$ experiment. Differences between sensitivity experiments will be discussed in a second step. We mostly limit our validation to Indo-Pacific SST, rainfall and wind stress in order to reduce the size of the paper.

\subsubsection{Mean-state}

The mean state of the SINTEX-F2 coupled model shows similarities with previous versions (Gualdi et al., 2003a) or with an equivalent version at lower resolution (Park et al., 2009).

Focusing first on SST, the tropics are mostly too warm and extra-tropics too cold (fig. 1a,b). Significant warm biases (over $2^{\circ} \mathrm{C}$ ) are found off the major coastal upwelling zones: in the Humbolt, California, Benguela and, to a lesser extent, Somalia current systems. Cold biases occur in the subtropical gyres where their amplitude exceeds $1^{\circ} \mathrm{C}$. Our simulation also shows a slight "cold tongue" bias in the central equatorial Pacific, but, due to improved coupling physics of Luo et al. (2005b), this bias is limited and does not extend into the western Pacific, as in previous versions of SINTEX (Guilyardi et al., 2003). The equatorial SST gradient in the central Pacific is nevertheless slightly amplified by this cold bias (fig. 2a) and is not as realistic as it was in the experiments of Luo et al. (2005b).

$2 \mathrm{~h} 31$ tropical precipitation is in good agreement with CMAP observations, even if the common "double ITCZ" problem is still present in the tropical basins (fig. 1c,d). In the Pacific, the precipitation maximum is correctly located over the warm pool, but model maxima exceed observations by $2 \mathrm{~mm}$ /day and extend too far east, particularly in the South Pacific Convergence Zone (SPCZ). Differences between $2 \mathrm{~h} 31$ and CMAP also show a northward shift of both the simulated ITCZ and SPCZ over most of the Pacific basin. In the Indian Ocean, the model underestimates the precipitation maximum off Sumatra with a bias of $2 \mathrm{~mm}$ /day and simulates excessive precipitation over the western Indian Ocean, forming an Indian Ocean Dipole (IOD)-like rainfall pattern. Over the western Indian Ocean, positive rainfall differences from observations also reach $2 \mathrm{~mm} /$ day in the south Arabian Sea and north of Madagascar. 
The structure and amplitude of the wind stress in the tropics are well reproduced by the model (fig. 1e,f); however, 2h31 shows several biases as far as the Pacific trade winds are concerned. They are too strong $\left(0.02\right.$ to $\left.0.03 \mathrm{~N} / \mathrm{m}^{2}\right)$ in the western Pacific, especially in the subtropics (near SPCZ and west of Hawaii islands), and too weak (up to $0.02 \mathrm{~N} / \mathrm{m}^{2}$ around $120^{\circ} \mathrm{W}$ at $10^{\circ} \mathrm{N}$ and $5^{\circ} \mathrm{S}$ ) in the eastern equatorial Pacific on both side of the ITCZ, including the Equator. This is in contrast to what is simulated by the majority of CGCMs and other versions of SINTEX, which display stronger trade winds over the eastern Pacific (Guilyardi et al., 2003). The equatorial biases in the eastern Pacific are also clearly illustrated in figure $2 \mathrm{~b}$. In the Indian Ocean, the main problem comes from the South Hemisphere trade winds that are too strong and extend northward up to just south of the Equator all along the basin. These surface wind errors are also seen in figure $2 \mathrm{~b}$ and imply that the zonal surface wind over the equatorial Indian Ocean is easterly throughout the seasonal cycle with disastrous consequences for a proper simulation of the Wyrtki Jets and IOD variability (see following sections).

\subsubsection{Seasonal Cycle}

The SST equatorial seasonal cycle in the observations and in $2 \mathrm{~h} 31$ experiment is shown in figure 3. Results are comparable to Park et al. (2009) and better than those discussed in Gualdi et al. (2003a), Luo et al. (2005b) and Tozuka et al. (2005). This suggests that the upgrade of ECHAM from version 4 to 5 was beneficial on this point. In the Pacific, the unrealistic semi-annual cycle of previous versions of SINTEX has disappeared and the amplitude of SST cooling almost agrees with observations $\left(23^{\circ}\right.$ instead of $\left.22^{\circ}\right)$. However, localization and timing are not always correct. In the eastern Pacific, for example, the seasonal SST cooling is not maintained until December generating a warm bias above $3^{\circ} \mathrm{C}$ west of $110^{\circ} \mathrm{W}$ during boreal fall. In addition, the cold SSTs do not extend off the South America coast and a permanent warm bias, exceeding $2{ }^{\circ} \mathrm{C}$, is found east of the Galapagos. On the contrary, the simulated summer cooling extends too far west and creates a seasonal equatorial cold tongue bias of $-1^{\circ} \mathrm{C}$ from $110^{\circ} \mathrm{W}$ to $160^{\circ} \mathrm{W}$ as discussed above. In the central and west Pacific, the seasonal displacement of the eastern edge of the warm pool is not properly simulated and the warm pool extends too far east causing a warm error of $1.5^{\circ} \mathrm{C}$ during boreal spring in $2 \mathrm{~h} 31$.

In the Indian Ocean, warm biases are dominant along the equator during nearly all months with the exception of the eastern part of the basin during late boreal summer and fall, which corresponds to the peak IOD season. The spring warming, before the Asian monsoon onset, is too strong with a warm bias of $1{ }^{\circ} \mathrm{C}$ all over the equatorial Indian Ocean. In summer, the seasonal cooling off Somalia associated with the Somali Jet is too weak and ends up in a localized, but intense warm error of $2^{\circ} \mathrm{C}$. Consistent with the existence of an IOD-like SST pattern in the Indian Ocean during boreal summer and fall, the northward component of the summer trade winds is too strong over the eastern Indian Ocean and is followed in fall by an abrupt cooling off Sumatra (fig. 3) and a weakened Wyrtki jet. All these Indian Ocean errors in the model seasonal climatology are consistent with the hypothesis that the positive windSST feedbacks at the heart of the IOD variability (Fischer et al., 2005) may also operate at the seasonal time scale in the SINTEX-F2 CGCM.

In conclusion, this new version of the SINTEX-F model presents many similarities to previous versions with some weaker points, especially in the Indian Ocean, and some improvements, particularly for the seasonal cycle in the eastern Pacific. Coupled models show 
a strong sensitivity to parameters tuning (Meehl et al., 2001a). It is therefore difficult to know if large-scale improvements (or worsening) in this upgraded version of SINTEX are due to a significant impact of changes in the physics, the resolution used or to a better (or worse) choice in the set of tuning parameters. However, knowing the past successes of the SINTEXF model for ENSO-related studies (Gualdi et al., 2003b; Guilyardi et al., 2004; Luo et al., 2005b; Luo et al., 2008), we are confident in the use of this new version for this study.

\subsection{Comparison of the different sensitivity experiments}

\subsubsection{Diurnal cycle}

As a first step in the comparison of our 4 simulations, we analyze in this subsection the impact of the vertical oceanic resolution on the diurnal SST variability and quantify differences of diurnal variability between configurations using 31 and 301 levels.

Figure 4 displays the model annual mean climatology of the amplitude of the SST diurnal cycle estimated as the mean value of the differences between SST maximum and minimum during 24 hours computed on-line for the $2 \mathrm{~h} 31$ and $2 \mathrm{~h} 301$ experiments. As expected, the amplitude of the SST diurnal cycle is much stronger in $2 \mathrm{~h} 301$ than in $2 \mathrm{~h} 31$. The simulation with 301 levels shows an amplitude of diurnal cycle of at least $0.5^{\circ} \mathrm{C}$ in the tropics, increasing to $0.8^{\circ} \mathrm{C}$ near the equator and with a maximum of $1.3^{\circ} \mathrm{C}$ in the eastern equatorial Pacific. By contrast, with 31 levels, the amplitude of the annual mean SST diurnal cycle is only $0.2^{\circ} \mathrm{C}$ in major parts of the tropics with a localized maximum of $0.4^{\circ} \mathrm{C}$ just west of the Galapagos. $2 \mathrm{~h} 301$ results are very close to the ones obtained by Bernie et al. (2007) in their forced model configuration. Furthermore, the spatial structure of $2 \mathrm{~h} 301$ annual mean diurnal cycle amplitude corresponds well to existing observed climatologies. Although its amplitude is slightly larger than the results of Clayson and Weitlich (2007), it is in a better agreement with the observations of Kawai and Wada (2007), Bellenger and Duvel (2009) and Vialard et al. (2009). In addition, observations may slightly underestimate the amplitude of the diurnal cycle whereas the model catches its maximum value systematically and this can explain, at least partly, the difference with the observations. In any case, the strong diurnal cycle observed in $2 \mathrm{~h} 301$ is advantageous for our purpose as it allows us to test the sensitivity of our results.

As expected, the change of coupling frequency of the SST (other aspects of the coupling being always performed every two hours) has a negligible impact on the diurnal insolation seen by the ocean and differences in the annual mean climatology of the SST diurnal cycle amplitude between $2 \mathrm{~h} 301(2 \mathrm{~h} 31)$ and $24 \mathrm{~h} 301(24 \mathrm{~h} 31)$ are therefore non-significant (figure not shown).

\subsubsection{Mean state and seasonal cycle}

The maps of differences between the annual mean SST climatologies of the four experiments clearly demonstrate that the change of the coupling frequency has a non-significant impact on the mean SST contrary to the change of the ocean vertical resolution (figs. 5c, d). Within a large tropical band $\left(30^{\circ} \mathrm{S}-30^{\circ} \mathrm{N}\right)$ differences between $2 \mathrm{~h} 31 / 24 \mathrm{~h} 31$ or $2 \mathrm{~h} 301 / 24 \mathrm{~h} 301$ are most often smaller than $\pm 0.05^{\circ} \mathrm{C}$ and exceed $-0.1^{\circ} \mathrm{C}$ only in a very small area of the west Pacific. In any case, these values are much smaller than the SST differences between experiments with 31 and 301 levels (figs. 5a, b). Increasing the vertical oceanic resolution has a direct impact on the representation of the diurnal cycle in the ocean and produces a warmer mean state (up 
to $1^{\circ} \mathrm{C}$ ) in the central and eastern Pacific and, more generally in the major coastal upwelling zones. In that way, our results are coherent with previous papers exploring the impact of the diurnal insolation (Danabasoglu et al., 2006; Bernie et al., 2008; Ham et al., 2010). These differences mostly suppress the small "cold tongue" bias observed in $2 \mathrm{~h} 31$ or $24 \mathrm{~h} 31$, but reinforce the warm bias in the eastern boundaries of the Pacific and Atlantic basins. The response of the equatorial Pacific is even more apparent if we compare the equatorial SST and wind stress as simulated in our experiments (fig. 2): it is almost impossible to see any difference in the SST or in the zonal wind stress when the coupling frequency of the SST is changed. However, the equatorial central warming in the 301 levels simulations improves the SST gradient and is associated with a decrease of zonal wind stress $\left(-0.01 \mathrm{~N} / \mathrm{m}^{2}\right)$ around the date line (in disagreement with the observations). The seasonal variations of the differences between the four simulations confirm our results on the mean state (fig. 6). Sending the SST to the atmosphere every 2 or 24 hours has a very weak impact on the equatorial SST seasonal cycle: differences rarely reach $\pm 0.2^{\circ} \mathrm{C}$. On the other hand, impact of the vertical resolution is significant, but relatively constant in time, and seasonal variations do not change the conclusions obtained from the maps presented in fig 5.

The conclusions we drew from the SST are valid for all fields (precipitation, heat fluxes, 850 $\mathrm{hPa}$ winds, salinity, sea level, depth of the $20^{\circ} \mathrm{C}$; not shown). Contrary to the vertical resolution in the ocean, the high SST coupling frequency has an insignificant impact on the mean state and seasonal variability of the tropical climate, as simulated by SINTEX-F2. Once again, we want to underline that our four experiments do see the solar diurnal cycle $(2 \mathrm{~h}$ coupling frequency for all atmospheric parameters). This result is therefore not contradictory with previous works of Bernie et al. (2008) and Ham et al. (2010) and was even expected with the 31 levels configuration because of its too low vertical resolution to correctly represent the SST diurnal cycle. Its robustness in the 301 levels cases, with its $1 \mathrm{~m}$ metre resolution near the surface allowing a realistic diurnal variability in the mixed layer, is more surprising, but it must not mask the key impact of the SST diurnal cycle on differences seen between 31 and 301 levels, in particular, in the response of the surface currents (not shown), as detailed by Bernie et al. (2008).

In summary, we can conclude, as Danabasoglu et al. (2006), that regarding the response of the annual mean state and seasonal cycle to the diurnal cycle, the atmosphere of our CGCM has no need to see the high frequency SST variability since this variability does not impact the system. However, these conclusions are not valid when we consider the interannual variability of our CGCM, as we will demonstrate in the next sections.

\section{ENSO characteristics}

In this section, we explore the interannual variability of the tropical Indo-Pacific region in our four simulations and quantify the impact of changes of SST coupling frequency and vertical oceanic resolution on ENSO statistics.

\subsection{SST Standard deviation}

The spatial patterns of SST interannual variability in the four experiments are almost identical (fig. 7). As expected, SST variability is the strongest in the central Pacific Ocean, with a maximum located on the Equator eastward of the date line. This maximum is slightly shifted westward compared with observations, but thanks to the coupling method of Luo et al. (2005b), this bias is largely reduced in comparison with results from most other CGCMs. 
SINTEX-F also shows some discrepancies with observations in the eastern Pacific. In all experiments, but especially when the SST coupling frequency is set to 24 hours, the region of maximum SST variability in the central Pacific (westward of $110^{\circ} \mathrm{W}$ ) is isolated from the other maximum off the coast of Peru while these two centers are obviously linked in observations. In the Indian Ocean, an unrealistic SST variability center (up to $1^{\circ} \mathrm{C}$ ) is found off Sumatra as in older versions of the model (Fischer et al., 2005). This bias is strongly phase-locked to the boreal fall, the peak season of IOD, and is linked to mean state errors of SST and wind in the eastern Indian Ocean which have been already discussed in the validation section.

More interestingly, the amplitude of the SST signal differs between our 4 experiments. First, moving from low to high vertical ocean resolution reduces the amplitude of the SST ENSO signal: $2 \mathrm{~h} 31$ maximum (up to $1.4^{\circ} \mathrm{C}$ ) in the equatorial Pacific is above observation estimates $\left(1^{\circ} \mathrm{C}\right)$, whereas $2 \mathrm{~h} 301$ matches the observed amplitude of ENSO with a maximum of $1.1^{\circ} \mathrm{C}$ (see fig. 7). This decrease of the standard deviation is also visible when we compare $24 \mathrm{~h} 31$ to 24h301. This change is somehow consistent with the results of Danabasoglu et al. (2006) and Ham et al. (2010) who observed a reduction of Niño3.4 SST standard deviation when they introduced the diurnal insolation in their CGCMs. Another striking result is that ENSO amplitude is also reduced by about $15 \%$ when the SST is sent to the atmosphere every $24 \mathrm{~h}$ instead of $2 \mathrm{~h}$. In addition, this result applies in experiments with a realistic (301 levels) or an extremely weak (31 levels) diurnal cycle. We note that this decrease of Niño3.4 variability has a relative weak seasonal cycle in the 31 level experiments (from -15 to $-20 \%$ ) whereas it is very weak in Feb-April and peaks between November and January $(-20 \%)$ in high vertical resolution simulations.

The standard deviations of Niño3 or Niño3.4 SST time series computed over a 40 -years sliding window confirm the robustness of our results established with the full length of our simulations (figs. 8a,b). Standard deviations computed from 301 levels experiments are always smaller than those of the corresponding twin experiment with 31 levels during the full length of the simulations. More precisely, a constant decrease of $-20 \%(-15 \%$ to $-20 \%)$ is observed for Niño3 (Niño3.4) SST standard deviations when comparing $2 \mathrm{~h} 31$ with $2 \mathrm{~h} 301$ or $24 \mathrm{~h} 31$ with $24 \mathrm{~h} 301$. Similar reductions of the ENSO signal, up to $-15 \%(-12 \%$ to $-20 \%)$ for Niño3 (Niño3.4) SST standard deviations, are obtained when sending the SST on daily basis (e.g. 24h31 and 24h301) instead of every 2 hours (e.g. $2 \mathrm{~h} 31$ and 2h301).

Fig. 8c gives the probability density function of Niño3.4 SST standard deviation estimated using a blockwise bootstrap procedure with a block length of 40-years (Politis, 1998) for the four experiments. This more robust calculation than a sliding window estimation confirms that Niño3.4 SST interannual variability is significantly decreased when the atmosphere sees the SST every 24 hours instead of $2 \mathrm{~h}$.

This subsection has shown that sending the SST on a daily basis systematically decreases ENSO variability by about $15 \%$ in our simulations. This impact is not related to the amplitude of the diurnal variability of the SST and is not an artifact of the seasonal cycle or the multidecadal variability since both have been carefully removed from the time series with the help of the STL procedure (see Section 2).

\subsection{ENSO frequency}

In this subsection, we address how ENSO frequency is modified by the high frequency SST coupling by applying the spectral diagnostics described in Section 2. 
The spectral density for the observations is estimated from the HadISST1.1 dataset for the period 1870-2006 after removal of the seasonal cycle and trend by the STL procedure as was done in the four simulations (figs. 9a, b). As, it is well documented in the literature (Guilyardi et al., 2009), the dominant period for the observed Niño3.4 SST index is about 4 years with a broad spectrum between 2 and 10 years, see fig. 9 a.

In agreement with previous studies using SINTEX model with a T106 atmospheric resolution (Guilyardi et al., 2004; Navarra et al., 2008), 2h31 spectrum matches the observed spectrum for all periods greater than one year and remains within the $99 \%$ confidence interval derived from the observations (dashed lines in fig. 9a). It peaks also around 4 years, but shows more power at periods between 1 and 6 years compared to observations. Surprisingly, the $24 \mathrm{~h} 31$ simulation shows 3 distinct maxima at 2, 3 and 6 years whereas a relative minimum is found at 4 years periodicity that is on or outside the $99 \%$ confidence interval computed from the observations estimates. Niño3.4 SST power spectrum simulated in $2 \mathrm{~h} 301$ is not much different from the observed one (with the exception of the periods from 2 to 3 years), while $24 \mathrm{~h} 301$ spectral estimates are again just on the lower limit of the $99 \%$ confidence interval for periods around 5 years (fig. $9 b$ ).

With 31 or 301 levels, experiments with high frequency coupling of the SST seem therefore to have more energy at almost all periods between a few months to 6 years. However, the width of the point-wise $99 \%$ confidence interval for the Niño3.4 spectrum estimated from the observations warns us against a too precise interpretation of the estimated spectra. To address this question quantitatively, figures $9 \mathrm{c}, \mathrm{d}$ show, on a logarithmic scale, the estimated spectral ratio of the Niño3.4 SST for the $2 \mathrm{~h} 31 / 24 \mathrm{~h} 31$ and $2 \mathrm{~h} 301 / 24 \mathrm{~h} 301$ experiments and the $90 \%$ point-wise tolerance interval (blues lines) for each ratio under the assumption that the two underlying spectra are the same (see Section 2). Consistent with figs. 9a,b, nearly all the estimated spectral ratios are positive for periods ranging from 2 to 6 years for both the $2 \mathrm{~h} 31 / 24 \mathrm{~h} 31$ and $2 \mathrm{~h} 301 / 24 \mathrm{~h} 301$ experiments. Moreover, $2 \mathrm{~h} 31 / 24 \mathrm{~h} 31$ spectral ratio falls outside the tolerance limits for periods around 4 and 2.5 years and $2 \mathrm{~h} 301 / 24 \mathrm{~h} 301$ ratio is just reaching the limit for its peak at 5 years.

In order to reinforce our interpretation of the spectra differences related to the change in SST coupling frequency, we now repeat the previous analysis for the estimated spectral ratio computed at each grid-point in the Indo-Pacific area, at periods matching the ENSO time scales (see fig. 10). Large and coherent regions in the central and eastern tropical Pacific show positive ratios which fall outside the $90 \%$ tolerance limits for both the $2 \mathrm{~h} 31 / 24 \mathrm{~h} 31$ and $2 \mathrm{~h} 301 / 24 \mathrm{~h} 301$ experiments. This confirms a systematic difference between the underlying spectra when high frequency coupling of the SST is introduced with both 31 and 301 levels. Interestingly, if we consider the periods 3 and 6 years, the spectral ratios between $2 \mathrm{~h} 31$ and $24 \mathrm{~h} 31$ show significant values in a large part of the central and eastern equatorial Pacific and, more specifically, in the Niño3.4 region. On the other hand, in the 301 levels experiments, the significant patterns in the eastern Pacific are shifted off Niño3.4, south to the equator. While these differences suggest that the response to the high frequency SST coupling is indeed not exactly the same with 31 and 301 levels, this also explains why the diagnostics shown on Fig. 9 and based solely on the Niño3.4 box have difficulties to catch the significant differences in ENSO frequency for the 301 levels experiments.

In summary, with 31 or 301 levels, experiments with high frequency SST coupling seem to have significantly more energy at almost all periods between a few months to 6 years and the shape of the Niño-34 SST spectrum is in better agreement with the observations, with a 
maximum around 4 years. The introduction of high-frequency SST coupling significantly improves the ENSO spectral characteristics in the SINTEX-F model.

\subsection{SST skewness and ENSO irregularity}

In observations, SST skewness exhibits positive values in the eastern Pacific and negative values in the western Pacific reflecting the fact that amplitude of El Niño events is stronger than amplitude of La Niña events (see fig. 11). Our four experiments exhibit a wide range of spatial variations of skewness in the tropical Pacific and most of them are markedly different from the patterns estimated from observations (fig. 11). Like other coupled models, SINTEX$F$ has difficulties in representing the skewness associated with ENSO nonlinearity (Burger and Stephenson, 1999; van Oldenborgh et al., 2005). However, contrasting features can be again highlighted when comparing experiments with daily or two hours SST coupling frequency. 24h31 shows negative values of skewness in nearly all the tropical Pacific, except in the far western Pacific (fig. 11c). This is the complete opposite picture to the observed ENSO irregularity. On the other hand, $2 \mathrm{~h} 31$ performs much better since many parts of the central and eastern Pacific are now covered by positive skewness (with the exception of the equator at $150^{\circ}-100^{\circ} \mathrm{W}$ ) and negative values are more or less organized in the form of a horseshoe pattern in much closer agreement with observations (fig. 11b). A more detailed investigation shows that the erroneous negative skewness found along the equator between $150^{\circ}-100^{\circ} \mathrm{W}$ in $2 \mathrm{~h} 31$ mostly affects the spring ENSO variability and not the peak phase of ENSO while the negative skewness of ENSO in $24 \mathrm{~h} 31$ concerns all the seasons, including boreal winter, the peak season of El Niño events (not shown). In other words, the $2 \mathrm{~h} 31$ experiment has a much more realistic skewness than $24 \mathrm{~h} 31$.

Figure 12 displays the evolution of the Niño3.4 SST anomalies during individual El Niño or La Niña events (occurring if the 5-month running means Niño 3.4 SST anomalies exceed 0.8 standard deviation for 6 months or more, from Trenberth, 1997) in 2h31 and 24h31 in order to complement the view given by the spatial distribution of skewness in figure 11. It is noteworthy that $2 \mathrm{~h} 31$ shows a large variety of El Niño events with Niño3.4 SST anomalies ranging from less than $1{ }^{\circ} \mathrm{C}$ to $3^{\circ} \mathrm{C}$. A large majority $(75 \%)$ of these warm events peaks between October and March. However, the known bias of SINTEX-F model regarding the spring-type El Niño events (Guilyardi et al., 2003; Terray et al., 2005; Tozuka et al., 2005) is still visible with $25 \%$ of the events peaking around June and decaying afterward. Note, however, that only 2 of these events are really "spring aborted" events ending in fall whereas others end after January. The evolution of El Niño events changes significantly in $24 \mathrm{~h} 31$ with a drastic reduction of the variety of events. In line with results of the above subsection about ENSO amplitude, SST anomalies do not exceed $1.2^{\circ} \mathrm{C}$. Strong warm events almost disappear with only one case showing SST anomalies slightly above $1.5^{\circ} \mathrm{C}$ instead of nine for $2 \mathrm{~h} 31$. This reduced diversity of El Niño events in $24 \mathrm{~h} 31$ is coherent with the difference in the spread of the probability density functions of $2 \mathrm{~h} 31$ and $24 \mathrm{~h} 31$ shown in fig. $8 \mathrm{c}$. The phase locking to the seasonal cycle is also modified with the change of the SST coupling frequency since the frequency of El Niño events peaking between October and March drops at 57\%, with more events peaking from April to August in 24h31. In addition, 24h31 shows more than a doubling of the aborted El Niño cases with 5 events ending before January. In summary, phase locking to the seasonal cycle becomes also much less realistic in $24 \mathrm{~h} 31$.

Results concerning La Niña events are slightly different. In $2 \mathrm{~h} 31$, contrary to the case of El Niño, the majority (54\%) of La Niña events are peaking in summer. The negative skewness found in the eastern Pacific in $2 \mathrm{~h} 31$, underlined in previous paragraphs, is therefore mostly related to the erroneous seasonal phase locking of La Niña events. If summer La Niña events 
are weaker in $24 \mathrm{~h} 31$ than in $2 \mathrm{~h} 31$, the decrease of amplitude between both experiments is not as spectacular as for El Niño events. $24 \mathrm{~h} 31$ still shows some strong La Niña episodes, with $7(2)$ events with anomalies exceeding $-1.5(-2)^{\circ} \mathrm{C}$ instead of $8(3)$ for $2 \mathrm{~h} 31$.

These results obtained from $2 \mathrm{~h} 31 / 24 \mathrm{~h} 31$ are not reproducible with experiments with 301 levels. Both $24 \mathrm{~h} 301$ and $2 \mathrm{~h} 301$ show some resemblance with the east Pacific pattern of observed skewness and the horseshoe further west, but with a weaker amplitude (figs. 11d, e). $2 \mathrm{~h} 301$ is slightly more realistic than $24 \mathrm{~h} 301$ in the western and central Pacific with a positive skewness 0.8 in the central equatorial Pacific, but the differences are probably not statistically different due to the limited number of years in the $2 \mathrm{~h} 301$ and $24 \mathrm{~h} 301$ simulations (only 65 years instead of 100 years for $2 \mathrm{~h} 31$ and 24h31). Therefore, uncertainties in the estimates of skewness are probably much too large to make any statements about the influence of the coupling frequency on the relative strength of El Niño and La Niña events in the high vertical ocean resolution experiments. However, it is also possible that these two configurations operate in a different dynamical regime than $2 \mathrm{~h} 31$ or $24 \mathrm{~h} 31$ due to the changes of the mean state and ENSO frequency discussed in the previous sections.

The next section addresses the strength of the feedback relationships involved in ENSO variability in order to provide a first plausible explanation for the observed changes in ENSO's amplitude, frequency and skewness when we moved from daily to two hours coupling frequency in our experiments.

\section{ENSO feedbacks}

ENSO evolution results from the interplay of a number of ocean-atmosphere feedbacks (Burgers et al., 2005; Wang and Picaut, 2004; Jin et al., 2006). Evaluating the balance of these various feedbacks will thus lead to a better understanding of the mechanisms at stake in the modifications of ENSO characteristics described in previous sections.

The analysis of these feedbacks, detailed in the present section, is based on a variety of MCAs covering both the Indian and Pacific Oceans between $40^{\circ} \mathrm{S}$ and $40^{\circ} \mathrm{N}$ of latitudes for different pairs of variables that are thought to play an important role in ENSO behaviour (see section 2.3). The leading modes of these MCAs we present in this section account for most of the Squared Covariance Fraction (SCF) between the various fields $(29 \%, 40 \%$ and up to $85 \%$ see Tables 2 to 5). They are therefore well separated from the lower MCA modes. This also suggests that these leading MCA patterns are stable and robust with respect to sampling errors and motivates our decision to include only these leading MCA modes in the following discussion.

\subsection{El Niño and Southern Oscillation coupling}

Embedded in the basic definition of ENSO itself, is the coupling between the SST and Sea Level Pressure (SLP) fields over the Indo-Pacific region (Trenberth and Caron, 2000). The feedback between the SST and the SLP in the four sensitivity experiments is thus the first to be explored.

The dominant features in the SLP and SST spatial patterns of the leading MCA modes in the various experiments are very similar with pair-wise spatial correlations exceeding 0.95 in all the cases (fig. 13). These maps are characteristic of the peak phase of El Niño events with warm SST anomalies in the equatorial and eastern Pacific surrounded by cold anomalies forming a "horseshoe" pattern. SLP modes are reminiscent of the Southern Oscillation with 
anomalies of opposite polarity between the eastern Pacific and the rest of the Indo-Pacific domain (Trenberth and Caron, 2000). These results are coherent with the high correlations ( $>$ 0.91, see Table 2) obtained between the corresponding EC time series and Niño34 SST time series and consistent with the first EOF pattern of interannual SST anomalies in the observations (Xue et al., 2000).

However, these maps underline again the impact of the SST coupling frequency on the intensity of ENSO with larger maxima and lower minima in the SST (with the notable exception of the IOD pattern) or SLP MCA patterns. The most striking results of this analysis concern the coupling strength between the SST and SLP modes that is significantly increased with $2 \mathrm{~h}$ SST coupling. As a first illustration, the SCF/NC/r for the first mode of the $2 \mathrm{~h} 31$ experiment are 70/11/0.78 compared to 59/7/0.68 for its $24 \mathrm{~h} 31$ counterpart (Table 2). Moreover, the first MCA mode accounts for 20\% (9.5\%) of the SST (SLP) variance in $2 \mathrm{~h} 31$, but for only $14.9 \%(8.4 \%)$ in $24 \mathrm{~h} 31$. The comparison of the $2 \mathrm{~h} 301$ and $24 \mathrm{~h} 301$ summary statistics gives similar results (Table 2). Thus, the SST and SLP fields are more strongly coupled at the interannual time scale when high frequency coupling of the SST is introduced, independently of the modification of the oceanic vertical resolution.

\subsection{Bjerknes feedback (air-sea coupling strength)}

This stronger ocean-atmosphere coupling is further demonstrated if we look at the results of MCAs between SST, OLR and zonal wind stress which may be used to measure the strength of the Bjerknes feedback and, more particularly, the intensity of the wind response to SST anomalies in the central and eastern Pacific (Bjerknes, 1969; Clarke, 1994; Neelin and Djikstra, 1995).

The leading SST patterns derived from these MCAs are not shown here because they all closely resemble the respective SST MCA patterns illustrated in Fig. 13 (pair-wise spatial correlations $>0.98$ and SST EC time series correlation $>0.96$ ). This exact correspondence may be taken as additional evidence of the physical meaning and robustness of the SST homogenous pattern illustrated in Fig. 13.

The corresponding heterogeneous zonal wind stress and OLR patterns are displayed in Figures $14 \mathrm{a}, \mathrm{b}, \mathrm{f}$ and $\mathrm{g}$, respectively. Once again, very few differences may be detected between the MCAs of the various experiments and maps are displayed only for $2 \mathrm{~h} 31$ and 24h31. The OLR patterns are characteristic of El Niño events with an increase of precipitation in the equatorial Pacific near the dateline and reduced rainfall over the maritime continent (e.g. see fig. 1 of Clarke, 1994).

Zonal wind stress maps are consistent with the observed leading EOF pattern for interannual wind anomalies (Xue et al., 2000). They display a kind of Gill-Matsuno type pattern in response to the warm SST anomaly (Matsuno 1966; Gill, 1980; Clarke, 1994) with a strong westerly anomaly centered at the equator and a weak easterly anomaly to the east. However, a symmetric pattern of easterlies is also found poleward on either side of the westerly equatorial anomaly suggesting the existence of two cyclonic cells to the west of the SST anomaly. Strong westerly anomalies are also observed at extratropical latitudes in both hemispheres, which are consistent with the excitation of atmospheric Rossby waves that propagate to higher latitudes from the equatorial Pacific heating source (Trenberth et al., 1998; Alexander et al., 2002).

Despite the similarity of the MCA patterns described above in the different experiments, the summary statistics for the SST-OLR and SST-zonal wind stress MCAs corroborate the hypothesis that the air-sea coupling strength at the interannual timescales are systematically 
enhanced in 2h SST coupling experiments: correlations, NC and SCF statistics and fractions of explained variance are systematically higher in $2 \mathrm{~h} 31$ and $2 \mathrm{~h} 301$ in comparison of $24 \mathrm{~h} 31$ and 24h301 (see Table 3).

Furthermore, the zonal wind stress response over the western equatorial Pacific has a stronger amplitude, a slightly wider latitudinal extent and is shifted eastward in $2 \mathrm{~h} 31$ compared to $24 \mathrm{~h} 31$ during the warm phase of ENSO (Figs. 14b and g). These eastward shift and latitudinal expansion of westerly anomalies in the western-central Pacific in relation to the eastern equatorial Pacific warming may provide a plausible physical explanation for the frequency and amplitude changes of the ENSO cycle in $2 \mathrm{~h} 31$ compared to $24 \mathrm{~h} 31$ (documented in the previous section) in the framework of equatorial wave dynamics (Kirtman, 1997; An and Wang, 2000; Wittenberg et al., 2006). As discussed in these studies, the amplitude and oscillation period of ENSO is highly dependent upon the spatial pattern and amplitude of the wind stress anomalies. As an illustration, a larger meridional scale and an eastward shift of the zonal wind stress anomaly, as noted in $2 \mathrm{~h} 31$, favor the generation of the higher meridional modes of the oceanic Rossby waves and the time for Rossby waves reaching the western boundary is also longer. Both factors may prolong the basin-wide thermocline adjustment time in a delayed oscillator framework and, thus, increase the ENSO period consistent with the 2h31 Niño-34 spectra displayed in figures 9a,c and 10a,b. However, these distinctive features are not so obvious when we compare the MCA patterns of $2 \mathrm{~h} 301$ and 24h301 (not shown). This is consistent with the less significant differences between the $2 \mathrm{~h} 301$ and $24 \mathrm{~h} 301$ SST Niño34 spectra (Figs. 9b and d).

\subsection{Wyrtki feedback (ocean feedback)}

Following the recharge oscillator theory (Jin, 1997), we are now exploring the MCA from the covariance matrix between the upper-ocean Heat Content (HC) and zonal wind stress anomalies. As our goal is to characterize the influence of the zonal wind stress anomalies on the evolution of the $\mathrm{HC}$, we discuss the $2 \mathrm{~h} 31$ and $24 \mathrm{~h} 31$ homogenous MCA pattern for zonal wind stress and heterogeneous MCA pattern for HC in figures 14.c and h. The $2 \mathrm{~h} 31$ and $24 \mathrm{~h} 31$ homogenous MCA patterns for zonal wind stress are very similar to the zonal wind stress maps shown in figures 14.b and g (not shown). Once again, the $\mathrm{HC}$ and zonal wind stress modes estimated from the other experiments display the same spatial features (not shown).

The first HC-zonal wind stress mode accounts for $69,54,53$ and $44 \%$ of the SCF for $2 \mathrm{~h} 31$, $24 \mathrm{~h} 31,2 \mathrm{~h} 301$ and $24 \mathrm{~h} 301$, respectively. Furthermore, this mode explains more than $15 \%$ of the total $\mathrm{HC}$ variance in the experiments and up to $26 \%$ for $2 \mathrm{~h} 31$. In all the experiments, the HC spatial patterns have large loadings in the tropical Pacific and describe a seesaw-like (e.g. a zonally tilting mode) variation between western and central-eastern tropical Pacific (Fig. 14c). Interestingly, the HC spatial pattern in this coupled mode resembles the first EOF of the depth of the $20^{\circ} \mathrm{C}$ isotherm or $\mathrm{HC}$ in the observations (see Fig. 3 of Meinen and McPhaden, 2000, and Fig. 3 of Hasegawa and Hanawa, 2003). The associated zonal wind stress patterns are exactly similar in structure to the zonal wind stress pattern from the SST-zonal wind stress MCAs (fig 14 b) and are therefore not re-discussed.

Furthermore, the correlations between the corresponding HC EC time series and the Niño-34 SST index show a maximum correlation in excess of 0.79 at zero time lag for $24 \mathrm{~h} 31$ and $24 \mathrm{~h} 301$ or with a time lead of one or two months of the Niño-34 SST time series for $2 \mathrm{~h} 31$ and $2 \mathrm{~h} 301$ (see Table 4), as in observations (Hasegawa and Hanawa, 2003). The spatial pattern illustrated in Fig. 14c is thus corresponding to the peak phase of El Niño events and illustrates 
one of the diagnostic equations of the recharge oscillator model which states that the zonal tilt of the thermocline across the equatorial Pacific reacts quasi-instantaneously to wind stress anomalies in the western-central Pacific (Jin, 1997; Burger et al., 2005).

Here again, SCF, NC and $r$ statistics are stronger in $2 \mathrm{~h} 31$ than in $24 \mathrm{~h} 31$, suggesting intensified Wyrtki and positive wind-thermocline-SST feedbacks (see Table 4). Note, however, that the strengthening of the Wyrtki feedback is not so obvious when we compare the results between $2 \mathrm{~h} 301$ and $24 \mathrm{~h} 301$ since the correlation coefficient between the first EC time series is, for example, slightly higher in $24 \mathrm{~h} 301$ than in $2 \mathrm{~h} 301$ (Table 4). Nevertheless, $\mathrm{SCF}, \mathrm{NC}$ statistics and the fractions of $\mathrm{HC}$ and zonal wind stress explained variance are still larger in $2 \mathrm{~h} 301$ in comparison with $24 \mathrm{~h} 301$. This is consistent with the hypothesis that the overall positive wind-thermocline-SST feedback is still enhanced in the $2 \mathrm{~h} 301$ experiment.

\subsection{Heat flux feedbacks}

Negative atmospheric feedbacks, mainly linked to the Short Wave Radiation (SWR) and the Latent Heat Flux (LHF), play also an important role in damping the ENSO signal and in the termination of El Niño events (Guilyardi et al., 2009; Sun et al., 2009; Lloyd et al., 2009, 2010).

Once again, the leading SST patterns of MCAs from the covariance matrix between the SST and the SWR or the LHF are not shown since they are similar in all respects to those displayed in Fig. 13. The corresponding SWR and LHF homogenous patterns of the four experiments are extremely similar and only those of $2 \mathrm{~h} 31$ and $24 \mathrm{~h} 31$ are displayed in Figs. $14 \mathrm{~d}$, e, $\mathrm{i}$ and $\mathrm{j}$. As expected from previous studies, SWR acts to damp the ENSO-related SST anomalies almost everywhere in the Pacific region (Figs. 14d and i). This is mostly associated with the cloud-shading effect and the eastward migration of the atmospheric deep convection from the maritime continent to the central Pacific at the height of the mature phase of El Niño events. The LHF homogenous vector has a large negative (positive) amplitude in the tropical eastern-central (western) Pacific (Figs. 14e and j) that can be traced back to wind speed variations (Chelton et al., 2001; Guilyardi et al., 2009) or specific humidity differences (Lloyd et al., 2010).

The coupling strength statistics for these leading MCA modes of the SWR and LHF with SST are also greater with SST high-frequency coupling in both the 31 and 301 levels configurations (see Table 5). However, the amplification of these SWR and LHF negative feedbacks seem not sufficient for compensating the effect of the strengthening of the overall positive feedback ENSO loop detailed in the previous subsections, as demonstrated in Section 4.

In conclusion, we demonstrated that all air-sea feedbacks (positive and negative) involved in ENSO physics are systematically reduced when the SST coupling frequency is decreased from $2 \mathrm{~h}$ to $24 \mathrm{~h}$. The whole ocean-atmosphere coupling strength at interannual timescale is therefore affected by the suppression of the intra-daily SST variability in $24 \mathrm{~h} 31$ and $24 \mathrm{~h} 301$, which leads to the changes in ENSO characteristics described in previous section.

\section{Conclusions and discussion}


This paper highlights the complexity of the scale interactions existing between the intra-daily and inter-annual variability of the tropical climate system. The most remarkable results of this work are:

- Even if the intra-daily and inter-annual time-scales are extremely distant, we showed that, at least in our CGCM, they constructively interfere through the coupling and the feedbacks existing between the ocean and the atmosphere and modify the characteristics of ENSO, the major mode of interannual climate variability in the tropics. Neglecting the SST intra-daily variability ends up, in our CGCM, to a systematic decrease of ENSO amplitude at almost all periods from a few months to 6 years. These differences are especially visible at ENSO periods (e.g. 3 to 5 years) with a decrease of SST variability of 15\%. Furthermore, ENSO frequency and skewness are also significantly modified and in better agreement with observations when SST intra-daily variability is directly taken into account in the coupling interface of our CGCM.

- These significant modifications of the SST interannual variability are not associated with any remarkable changes in the mean state or the seasonal variability in our sensitivity experiments on the SST coupling frequency. Thus, these modifications of ENSO cannot be explained by a rectification of the mean state as it is usually advocated in recent studies focusing on the diurnal cycle (Danabasoglu et al., 2006; Ham et al., 2010).

- Detailed analysis demonstrated that these changes may be at least partly explained by a systematic strengthening of the air-sea feedbacks involved in ENSO physics when the high frequency SST variability is included: El Niño - Southern Oscillation coupling (SST/SLP), Bjerknes feedback (SST/OLR or zonal wind stress), Wyrtki feedback (zonal wind stress/upper-ocean heat content), but also heat fluxes feedbacks (SST/short wave or latent heat fluxes) are amplified with SST high frequency coupling and contribute globally to enhance ENSO variability.

- In our CGCM, nearly all these results (excepted for SST skewness) are independent of the amplitude of the intra-daily variability of the SST (e.g. SST diurnal cycle). Conclusions drawn from experiments with 301 oceanic vertical levels, characterized by a strong response to diurnal solar forcing, are similar to those obtained from the default 31 levels ocean configuration of our CGCM that exhibits a very weak response to the solar diurnal forcing. This result therefore suggests that the intra-daily SST variability can have an impact through the SST high frequency coupling even in coupled models that are not reproducing correctly oceanic response to the diurnal solar cycle. This suggests that the systematic deterioration of the air-sea coupling by a daily exchange of SST information is cascading toward the major mode of tropical variability, i.e. ENSO.

The recent work of Wittenberg (2009) with the GFDL CM2.1 CGCM sheds a new light on ENSO long-term variability and raises the question of the pertinence to work on ENSO simulations whose length is not, at least, a few centuries. The GFDL CM2.1 shows a strong multi-decadal variability suggesting that its ENSO characteristics are changing a lot from century to century. With such CGCM, it is thus justified to wonder if the differences we see when changing the SST coupling frequency are not a simple accident related to the multidecadal variability. A list of arguments may be provided in order to suggest that this is not the case as far as our CGCM is concerned and that our results are robust:

- We developed powerful statistical methods, including an original technique to extract the interannual signal (e.g. the STL procedure) and powerful spectral tests in order to determine the level of significance of the simulated ENSO changes discussed in this paper (see Section 2). 
- Figure 8 of 40-year sliding-window and bootstrap estimates of the probability density function of the Niño3.4 SST standard deviations demonstrates that our results are robust during the full length of our experiments and are statistically significant.

- Finally, Wittenberg (2011, personal communication) showed that, in the GFDL CM2.1, the strength of the air-sea feedbacks involved in ENSO physics is remarkably constant although Niño3.4 SST is affected by a strong multi-decadal variability. Thus, the systematic decrease of all statistical diagnostics quantifying the strength of air-sea interactions when changing the SST coupling frequency from $2 \mathrm{~h}$ to $24 \mathrm{~h}$ in simulations with 31 or 301 levels (see Tables 2 to 5), further attests the robustness of the modifications of ENSO in the framework of our CGCM.

The SST high frequency coupling is thus appearing as an independent and additional way to modify ENSO behaviour in CGCMs without any changes in the atmospheric or oceanic components of the coupled model, as usually done in previous studies (Meehl et al., 2001a; Danabasoglu et al., 2006; Navarra et al., 2008; Neale et al., 2008). This is entirely consistent with the conceptual framework for time and space scale interactions in the climate system proposed by Meehl et al. (2001b) in which forcing-response processes from shorter time scales can impact the interannual variability through a variety of up-scale links. Thus, the present study highlights the importance of up-scale interactions for improving state-of-the-art simulations of the tropical climate.

However, the present work is also raising several important questions that should be investigated in future studies.

A first surprising result of this study is the relative weakness of the impact to the (strong) intra-daily SST variability in the 301 levels twin experiments in comparison with the results obtained with the 31 levels experiments. In other words, it is difficult to understand why the changes of ENSO, when modifying the SST coupling frequency, are not reflecting in some way the stronger SST intra-daily variability of the 301 experiments. Could it be explained by the incapacity of the atmospheric model to respond correctly to the high frequency variability of the SST? Could it be explained by the slight differences in the mean state existing between the experiments with 31 or 301 levels? For example, is the weak equatorial cold tongue bias seen in the 31 oceanic levels configuration exciting the SST or wind intra-daily variability through the presence of stronger SST gradients in the western equatorial Pacific that could impact ENSO in a more effective way that in the 301 levels oceanic configuration?

Second, all these results are based on a single coupled model. It would be interesting to explore the robustness of our conclusions with other coupled models or with the same model but with different (atmosphere or ocean) resolutions. Previous works on ENSO have often been performed with coarse model resolution and pointed out the key role of the atmosphere in setting ENSO characteristics (Guilyardi et al., 2004). We could, for example, wonder if the sensitivity to the air-sea coupling will increase with higher resolution as small spatial scales are better resolved and high frequency variability is also enhanced in high resolution coupled models. Taking into account that more than half of the CMIP3 coupled models are still exchanging atmospheric and oceanic information just once a day, conducting the sensitivity experiments reported here with other CGCMs is definitively a priority task and a fruitful pathway for improving current coupled models in the future.

Third, we did not address the role of the stochastic atmospheric forcing on ENSO variability in our four experiments, which probably play an important role, at least, to explain some of 
the differences between the $2 \mathrm{~h} 31$ (2h301) and 24h31 (24h301) experiments. As an illustration, we can expect to modify the skewness and seasonal phase locking (and also the variance) of ENSO indices, when the high frequency coupling of the SST is activated, by changing the High-Frequency (HF) atmospheric variability such as the MJO and the Westerly Wind Events (WWEs) or by changing the nonlinear relationships between these HF ENSO precursors and the Low-Frequency (LF) ENSO precursors, such as the heat content in the equatorial Pacific or the LF wind over the western Pacific before ENSO onset (Kug et al., 2010). We aim to get more insight on the possible influence of the atmospheric noise forcing over the whole Pacific in our simulations, especially in the form of wind variations, in a forthcoming study. Such study must also be carried out in order to describe comprehensively how the shorter time scales are modified by the SST high-frequency coupling and how these modifications are able to interfere with the longer time scales without any changes of the mean state or the seasonal cycle in our experiments when the high frequency coupling of the SST is activated in our CGCM.

Fourth, taking into account the significant changes in ENSO characteristics in our experiments, the possible impact of the SST high frequency coupling on the associated ENSO teleconnections in our CGCM is also a very interesting subject to be studied in future works.

\section{Acknowledgments:}

This work is a part of the EU-Japan collaboration build around the SINTEX-F coupled model. It is also a contribution to the MOU between the Earth Simulator Center (ESC), CNRS and IFREMER. All the computationally expensive experiments analysed in the study were performed on the Earth simulator. Our sensitivity experiments with 301 levels in the ocean have been double thanks to the outstanding computational performances offered by this unique supercomputer. S. Masson and G. Madec were supported by ANR (INLOES project). $\mathrm{P}$. Terray benefited from the financial support from the Indo-French CEFIPRA project $\left(\mathrm{N}^{\circ}\right.$ 3907/1). Many thanks to R. Benshila, C. Talandier, A. Caubel, E. Maisonnave, M.A. Foujols, C. Levy, Y.Meursedoif, F. Pinsard, C. Deltel, S. Denvil and P. Brochard who have come to the ESC to implement, optimize and run the simulations. Their visit at the ESC was greatly facilitated by the kind help of A. Kurita, R. Itakura, A. Toya and M.-E. Demory. Graphics have been prepared using the SAXO package of S. Masson. 


\section{References}

- AchutaRao, K., and Sperber, K. (2002). Simulation of the El Niño Southern Oscillation: Results from the coupled model intercomparison project. Climate Dynamics 19, 191-209.

- Achutarao, K., and Sperber, K.R. (2006). ENSO simulation in coupled ocean-atmosphere models: are the current models better? Climate Dynamics 27, 1-15.

- Alexander, M.A., et al. (2002) The Atmospheric Bridge : the Influence of ENSO Teleconnections on Air-Sea Interaction over the Global Oceans. J. Climate, 15, 2205-2231.

- An, S.-I., and B. Wang (2000) Interdecadal change of the structure of the ENSO mode and its impact on ENSO frequency. J. Climate, 13, 2044-2055.

- Barnier, B., Madec, G., Penduff, T., Molines, J.-M., Treguier, A.-M., Le Sommer, J., Beckmann, A., Biastoch, A., Böning, C., et al. (2006). Impact of partial steps and momentum advection schemes in a global ocean circulation model at eddy-permitting resolution. Ocean Dynamics 56, 543-567.

- Bellenger, H., and Duvel, J.P. (2009). An Analysis of Ocean Diurnal Warm Layers over Tropical Oceans. J. Climate 22, 3629-646.

- Belmadani, A., Dewitte, B., and An, S.-I. (2010). ENSO Feedbacks and Associated Time Scales of Variability in a Multimodel Ensemble. Journal of Climate 23, 3181-3204.

- Bernie, D.J., Guilyardi, E., Madec, G., Slingo, J.M., and Woolnough, S.J. (2007). Impact of resolving the diurnal cycle in an ocean--atmosphere GCM. Part 1: a diurnally forced OGCM. Climate Dynamics 29, 575-590.

- Bernie, D.J., Guilyardi, E., Madec, G., Slingo, J.M., Woolnough, S.J., and Cole, J. (2008). Impact of resolving the diurnal cycle in an ocean--atmosphere GCM. Part 2: A diurnally coupled CGCM. Climate Dynamics 31, 909-925.

- Bernie, D.J., Woolnough, S.J., Slingo, J.M., and Guilyardi, E. (2005). Modeling diurnal and intraseasonal variability of the ocean mixed layer. Journal of Climate 18, 1190-1202.

- Bjerknes, J. (1969), Atmospheric teleconnections from the equatorial Pa-cific, Mon. Weather Rev., 97, 163 - 172.

- Bretherton, C., Smith, C. and Wallace, J. (1992) An intercomparison of methods for finding coupled patterns in climate data. J. Climate, 5, 541-560.

- Brown, J.N., Fedorov, A.V., and Guilyardi, E. (2011) How well do coupled models replicate ocean energetics relevant to ENSO? Climate Dynamics , DOI: 10.1007/s00382-010-0926-8

- Burgers, G., and D. B. Stephenson (1999), The "normality" of El Niño, Geophys. Res. Lett., 26(8), 1027-1030, doi:10.1029/1999GL900161

- Burgers, G., F.-F. Jin, and G. J. Oldenborgh (2005), The simplest ENSO recharge oscillator, Geophys. Res. Lett., 32, L13706, doi:10.1029/2005GL022951.

- Chelton, Dudley B., and Coauthors, 2001: Observations of Coupling between Surface Wind Stress and Sea Surface Temperature in the Eastern Tropical Pacific. J. Climate, 14, 14791498.

- Clarke, A. J., 1994: Why are surface equatorial winds anomalously westerly under anomalous large-scale convection? J. Climate, 7, 1623-1627

- Clayson, C.A., and Weitlich, D. (2007). Variability of tropical diurnal sea surface temperature. Journal of Climate 20, 334-352.

- Cleveland RB, Cleveland WS, McRae JE, Terpenning I (1990) A Seasonal-Trend Decomposition Procedure Based on Loess (with Discussion). J Official Statistics 6:3-73.

- Collins, M., An, S.I., Cai, W., Ganachaud, A., Guilyardi, E., Jin, F.F., Jochum, M., Lengaigne, M., Power, S., and Timmermann, A. (2010). The impact of global warming on the tropical Pacific Ocean and El Niño. Nature Geoscience 3, 391-97. 
- Danabasoglu, G., Large, W.G., Tribbia, J.J., Gent, P.R., Briegleb, B.P., and McWilliams, J.C. (2006). Diurnal coupling in the tropical oceans of CCSM3. Journal of climate 19, 2347365 .

- Davey, M., Huddleston, M., Sperber, K., Braconnot, P., Bryan, F., Chen, D., Colman, R., Cooper, C., Cubasch, U., and Delecluse, P. (2002). STOIC: a study of coupled model climatology and variability in tropical ocean regions. Climate Dynamics 18, 403-420.

- Delecluse, P., Davey, M.K., Kitamura, Y., Philander, S.G.H., Suarez, M., and Bengtsson, L. (1998). Coupled general circulation modeling of the tropical Pacific. J Geophys Res 103, 14. - Diggle PJ (1990) Time series : a biostatistical introduction. Chapter 4, Clarendon Press, Oxford.

- Fischer AS, Terray P, Delecluse P, Gualdi S, Guilyardi E (2005) Two Independent Triggers for the Indian Ocean Dipole/Zonal Mode in a Coupled GCM. J. Climate, 18, 3428-3449.

- Gill AE (1980) Some simple solutions for the heat induced tropical circulation. Q J Meteorol Soc 106:447-462

- Gualdi, S., Guilyardi, E., Navarra, A., Masina, S., and Delecluse, P. (2003b). The interannual variability in the tropical Indian Ocean as simulated by a CGCM. Climate Dynamics 20, 567-582.

- Gualdi, S., Navarra, A., Guilyardi, E., and Delecluse, P. (2003a). Assessment of the tropical Indo-Pacific climate in the SINTEX CGCM. Annals of Geophysics 46

- Guilyardi, E. (2006). El Niño--mean state--seasonal cycle interactions in a multi-model ensemble. Climate Dynamics 26, 329-348.

- Guilyardi, E., Braconnot, P., Jin, F.F., Kim, S.T., Kolasinski, M., Li, T., and Musat, I. (2009). Atmosphere feedbacks during ENSO in a coupled GCM with a modified atmospheric convection scheme. Journal of Climate 22, 5698-5718.

- Guilyardi, E., Delecluse, P., Gualdi, S., and Navarra, A. (2003). Mechanisms for ENSO phase change in a coupled GCM. Journal of Climate 16, 1141-158.

- Guilyardi, E., Gualdi, S., Slingo, J., Navarra, A., and Delecluse, P. (2004). Representing El Niño in coupled ocean--atmosphere GCMs: The dominant role of the atmospheric component.

J. Climate 17, 4623-29.

- Guilyardi, E., Wittenberg, A., Fedorov, A., Collins, M., and Wang, C. (2009). UNDERSTANDING EL NIÑO IN OCEAN--ATMOSPHERE GENERAL CIRCULATION MODELS. Bull. Amer. Meteor. Soc 90, 325-340.

- Ham, Y.G., Kug, J.S., Kang, I.S., Jin, F.F., and Timmermann, A. (2010). Impact of diurnal atmosphere--ocean coupling on tropical climate simulations using a coupled GCM. Climate Dynamics 34, 905-917.

- Hasegawa, T., and K. Hanawa, (2003) Heat content Variability related to ENSO events in the Pacific. J. Phys. Oceanogr., 33, 407-421.

- Jin, F.F. (1997) An equatorial ocean recharge paradigm for ENSO. Part I: Conceptual model. J. Atmos. Sci., 54, 811-829.

- Jin, E.K., Kinter, J.L., Wang, B., Park, C.K., Kang, I.S., Kirtman, B.P., Kug, J.S., Kumar, A., Luo, J.J., and Schemm, J. (2008). Current status of ENSO prediction skill in coupled ocean--atmosphere models. Climate Dynamics 31, 647-664.

- Jin, F.-F., Kim, S.T., and Bejarano, L. (2006). A coupled-stability index for ENSO. Geophys Res Lett 33, L23708-8.

- Jochum, M., Danabasoglu, G., Holland, M., Kwon, Y.O., and Large, W.G. (2008). Ocean viscosity and climate. J Geophys Res 113, C06017.

- Kawai, Y., and Wada, A. (2007). Diurnal sea surface temperature variation and its impact on the atmosphere and ocean: a review. Journal of Oceanography 63, 721-744.

- Kirtman, B.P., 1997: Oceanic Rossby waves dynamics and the ENSO period in a coupled model. $J$. Clim., 10, 1690-1704. 
- Kug, J.-S., K.-P. Sooraj, T. Li, and F.-F. Jin (2010), Precursors of the El Niño/La Niña onset and their interrelationship, J. Geophys. Res., 115, D05106, doi:10.1029/2009JD012861.

- Lin, J.L. (2007). The double-ITCZ problem in IPCC AR4 coupled GCMs: Oceanatmosphere feedback analysis. Journal of Climate 20, 4497-4525.

- Lloyd, J., Guilyardi, E., and Weller, H. (2010). The role of atmosphere feedbacks during ENSO in the CMIP3 models. Part II: using AMIP runs to understand the heat flux feedback mechanisms. Climate Dynamics , 1-22.

- Lloyd, J., Guilyardi, E., Weller, H., and Slingo, J. (2009). The role of atmosphere feedbacks during ENSO in the CMIP3 models. Atmospheric Science Letters 10, 170-76.

- Luo, J.J., Masson, S., Behera, S., Delecluse, P., Gualdi, S., Navarra, A., and Yamagata, T. (2003). South Pacific origin of the decadal ENSO-like variation as simulated by a coupled GCM. Geophys. Res. Lett 30, 2250.

- Luo, J.J., Masson, S., Behera, S., Shingu, S., and Yamagata, T. (2005a). Seasonal climate predictability in a coupled OAGCM using a different approach for ensemble forecasts. Journal of Climate 18, 4474-497.

- Luo, J.J., Masson, S., Roeckner, E., Madec, G., and Yamagata, T. (2005b). Reducing climatology bias in an ocean--atmosphere CGCM with improved coupling physics. Journal of Climate 18, 2344-360.

- Luo, J.J., Masson, S., Behera, S.K., and Yamagata, T. (2008). Extended ENSO predictions using a fully coupled ocean--atmosphere model. Journal of Climate 21, 84-93.

- Madec G (2008) Madec G (2008) "NEMO ocean engine". Note du Pole de modélisation, Institut Pierre-Simon Laplace (IPSL), France, No 27 ISSN No 1288-1619.

- Masson, S., Luo, J.J., Madec, G., Vialard, J., Durand, F., Gualdi, S., Guilyardi, E., Behera, S., Delecluse, P., et al. (2005). Impact of barrier layer on winter-spring variability of the southeastern Arabian Sea. Geophys. Res. Lett 32

- Manganello JV, Huang B (2009) The influence of systematic errors in the Southeast Pacific on ENSO variability and prediction in a coupled GCM. Clim. Dyn., 32, 1015-1034, DOI 10.1007/s00382-008-0407-5.

- Matsuno, T., 1966: Quasi-geostrophic motions in the equatorial area. J. Meteor. Soc. Japan, 44, 25-43.

- McPhaden, M.J., Zebiak, S.E., and Glantz, M.H. (2006). ENSO as an integrating concept in earth science. Science 314, 1740-45.

- Meehl, G.A., Gent, P.R., Arblaster, J.M., Otto-Bliesner, B.L., Brady, E.C., and Craig, A. (2001a). Factors that affect the amplitude of El Niño in global coupled climate models. Climate Dynamics 17, 515-526.

- Meehl GA, Lukas R, Kiladis GN, Wheeler M, Matthews A, Weickmann KM (2001b) A conceptual framework for time and space scale interactions in the climate system. Clim. Dyn., 17, 753-775.

- Meinen, C.S., and M.J. McPhaden, (2000) Observations of warm water volume changes in the equatorial Pacific and their relationship to El Niño and La Niña. J. Climate. 13, 35513559 .

- Molines J.M., B. Barnier, T. Penduff, L. Brodeau, A.M. Treguier, S. Theetten and Gurvan Madec (2006), Definition of the global $1 / 2^{\circ}$ experiment with CORE interannual forcing, ORCA05-G50. LEGI report November 2006. LEGI-DRA-1-11-2006, http://www.ifremer.fr/lpo/drakkar/drakkar/configs/ORCA05/orca05_G50.pdf

- Morcrette, J.-J., L. Smith, and Y. Fouquart, 1986: Pressure and temperature dependence of the absorption in longwave radiation parameterizations. Beitr. Phys. Atmos., 59, 455-469.

- Morissey ML (1990) An evaluation of ship data in the equatorial western Pacific. Journal of Climate, 3, 99-112. 
- Navarra, A., Gualdi, S., Masina, S., Behera, S., Luo, J.J., Masson, S., Guilyardi, E., Delecluse, P., and Yamagata, T. (2008). Atmospheric horizontal resolution affects tropical climate variability in coupled models. Journal of Climate 21, 730-750.

- Neale, R.B., Richter, J.H., and Jochum, M. (2008). The impact of convection on ENSO: From a delayed oscillator to a series of events. Journal of Climate 21, 5904-924.

- Neelin, J. D. and H. A. Dijkstra, 1995: Ocean-atmosphere interaction and the tropical climatology. Part I: The angers of flux correction. J. Climate, 8, 1325-1342

- Nordeng, T. E. (1994): Extended versions of the convective parameterization scheme at ECMWF and their impact on the mean and transient activity of the model in the tropics . Technical Memorandum 206, ECMWF, Reading, UK.

- Park, W., Keenlyside, N., Latif, M., Ströh, A., Redler, R., Roeckner, E., and Madec, G. (2009). Tropical Pacific Climate and Its Response to Global Warming in the Kiel Climate Model. Journal of Climate 22, 71-92.

- Philip, S.Y., Collins, M., van Oldenborgh, G.J., and van den Hurk, B. (2010). The role of atmosphere and ocean physical processes in ENSO in a perturbed physics coupled climate model. Ocean Sci 6, 441-459.

- Politis DN (1998) Computer intensive methods in statistical analysis. IEEE signal processing magazine, 15, 39-55.

- Rayner, N.A., Parker, D.E., Horton, E.B., Folland, C.K., Alexander, L.V., Rowell, D.P., Kent, E.C., and A. Kaplan, 2003: Global analyses of sea surface temperature, sea ice, and night marine air temperature since the late nineteenth century. J. Geophys. Res., 108 (D14), 4407, doi:10.1029/2002JD002670.

- Reichler, T., and Kim, J. (2008). How well do coupled models simulate today's climate? Bulletin of the American Meteorological Society 89, 303-311.

- Roeckner, E. and Meteorologie, M. -P. F. (2003). The atmospheric general circulation model ECHAM5: Part 1: Model description. Max-Planck-Institut für Meteorologie.

- Roeckner, E., Brokopf, R., Esch, M., Giorgetta, M., Hagemann, S., Kornblueh, L., Manzini, E., Schlese, U., and Schulzweida, U. (2004). The atmospheric general circulation model ECHAM5 Part II: Sensitivity of simulated climate to horizontal and vertical resolution. MaxPlanck-Institute for Meteorology, MPI-Report 354

- Slingo, J., Inness, P., Neale, R., Woolnough, S., and Yang, G. (2003). Scale interactions on diurnal toseasonal timescales and their relevanceto model systematic errors. Annals of Geophysics

- Sun, D. Z., Yu, Y., \& Zhang, T. (2009). Tropical water vapor and cloud feedbacks in climate models: A further assessment using coupled simulations. Journal of Climate, 22(5), 1287-1304.

- Terray P, Guilyardi E, Fischer AS, Delecluse P (2005) Dynamics of the Indian Monsoon and ENSO Relationships in the SINTEX global Coupled Model. Clim. Dyn., 24, 145-168.

- Terray P (2010) Southern Hemisphere extra-tropical forcing: a new paradigm for El NiñoSouthern Oscillation. Clim. Dyn., doi:10.1007/s00382-010-0825-z.

- Tiedtke, M. (1989). A comprehensive mass flux scheme for cumulus parameterization in large-scale models. Monthly Weather Review 117, 1779-1800.

- Tozuka, T., Luo, J.J., Masson, S., Behera, S.K., and Yamagata, T. (2005). Annual ENSO simulated in a coupled ocean-atmosphere model. Dynamics of Atmospheres and Oceans 39, 41-60.

- Timmermann, R., Goosse, H., Madec, G., Fichefet, T., Ethe, C., and Duliere, V. (2005). On the representation of high latitude processes in the ORCA-LIM global coupled sea ice-ocean model. Ocean Modelling, 8(1-2), 175-201.

- Trenberth, K.E. (1997) The Definition of El Niño. Bull. Amer. Met. Soc., 78, 2771-2777. 
- Trenberth, K.E., et al., 1998: Progress during TOGA in understanding and modeling global teleconnections associated with tropical sea surface temperatures. J. Geophys. Res., 103, 14291-14324.

- Trenberth, K.E., and J.M. Caron, 2000: The Southern Oscillation revisited: Sea Level Pressures, Surface Temperatures, and Precipitation. J. Climate, 13, 4358-4365.

- Van Oldenborgh, G.J., S.Y. Philip, and M. Collins (2005) El Niño in a changing climate: a multi-model study, Ocean Science, 1, 81-95, SRef-ID: 1812-0792/os/2005-1-8

- Valcke, 2006: OASIS3 User Guide (prism_2-5). CERFACS Technical Report TR/CMGC/06/73, PRISM Report No 3, Toulouse, France. 60 pp

- Vialard, J., Duvel, J.P., Mcphaden, M.J., Bouruet-Aubertot, P., Ward, B., Key, E., Bourras, D., Weller, R., Minnett, P., et al. (2009). Cirene: Air-Sea Interactions in the SeychellesChagos Thermocline Ridge Region. Bulletin of the American Meteorological Society 90, 4561.

- Vialard, J., Foltz, G., McPhaden, M., Duvel, J.P., and de Boyer Montégut, C. (2008). Strong Indian Ocean sea surface temperature signals associated with the Madden-Julian Oscillation in late 2007 and early 2008. Geophys. Res. Lett 35

- von Storch H. and F.W. Zwiers (1999) Statistical Analysis in Climate Research. Cambridge University Press, 484 pp, ISBN 0521450713.

- Wang, C., and J. Picaut, 2004: Understanding ENSO physics - A review. In: Earth's Climate: The Ocean-Atmosphere Interaction. C. Wang, S.-P. Xie, and J. A. Carton, Eds., AGU Geophysical Monograph Series, 147:21-48.

- Watanabe, M., Chikira, M., Imada, Y., \& Kimoto, M. (2011). Convective control of ENSO simulated in MIROC. Journal of Climate, 24(2), 543-562.

- Welch PD (1967) The use of Fast Fourier Transform for the estimation of power spectra: a method based on time averaging over short, modified periodograms. IEEE Transactions on Audio and Electroacoustics, 15, 70-73.

- Wittenberg, A.T., Rosati, A., Lau, N.-C., and Ploshay, J.J. (2006). GFDL's CM2 Global Coupled Climate Models. Part III: Tropical Pacific Climate and ENSO. Journal of Climate 19, 698-722.

- Wittenberg, A.T. (2009). Are historical records sufficient to constrain ENSO simulations. Geophys. Res. Lett 36, L12702.

- Woolnough, S.J., Vitart, F., and Balmaseda, M.A. (2007). The role of the ocean in the Madden--Julian Oscillation: Implications for MJO prediction. Quarterly Journal of the Royal Meteorological Society 133, 117-128.

- Xue, Y., A. Leetmaa, and M. Ji (2000), ENSO prediction with Markov model: The impact of sea level, J. Clim., 13, 849-871

- Yeh, S.W., Dewitte, B., Yim, B.Y., and Noh, Y. (2010). Role of the upper ocean structure in the response of ENSO-like SST variability to global warming. Climate Dynamics , 1-15.

- Zhang, Y., J.R. Norris, and J.M. Wallace (1998) Seasonality of large scale atmosphereocean interaction over the North Pacific. J. Climate, 11, 2473-2481. 


\section{Figure captions}

Figure 1: Indo-Pacific mean state validation. a) $2 \mathrm{~h} 31 \mathrm{SST}\left({ }^{\circ} \mathrm{C}\right) .100$-year annual mean (years 11-110), $\mathrm{CI}=0.5^{\circ} \mathrm{C} . \mathrm{b}$ ) SST difference $\left({ }^{\circ} \mathrm{C}\right.$ ) between $2 \mathrm{~h} 31$ (years $11-110$ ) and the Tropical rainfall measuring mission Microwave Imager (TMI) (years 1998-2009). $\mathrm{CI}=0.5^{\circ} \mathrm{C}$. c) $2 \mathrm{~h} 31$ precipitation (mm/day). 100-year annual mean (years 11-110), CI=1mm/day. d) Precipitation difference (mm/day) between $2 \mathrm{~h} 31$ (years 11-110) and the Climate prediction center Merged Analysis of Precipitation (CMAP) (years 1979-2009). CI=1mm/day. e) $2 \mathrm{~h} 31$ surface wind stress vectors and module $\left(\mathrm{N} / \mathrm{m}^{2}\right)$. 100-year annual mean (years $\left.11-110\right), C I=0.02 \mathrm{~N} / \mathrm{m}^{2} . \mathrm{b}$ ) surface wind stress vectors and module difference $\left(\mathrm{N} / \mathrm{m}^{2}\right.$ ) between $2 \mathrm{~h} 31$ (years 11-110) and ECMWF ReAnalyses (ERA) Interim (years 1989-2009). CI $=0.005 \mathrm{~N} / \mathrm{m}^{2}$

Figure 2: Annual mean of equatorial sections (averaged between $2^{\circ} \mathrm{S}-2^{\circ} \mathrm{N}$ ) in the Indo-Pacific basin for $2 \mathrm{~h} 31$ (years 11-110) in black, 24h31 (years 11-110) in blue, 2h301 (years 11-75) in orange, 24h301 (years 11-75) in green and ERA-Interim (years 1989-2009) in pink. a) SST in ${ }^{\circ} \mathrm{C}$. b) Zonal surface wind stress in $\mathrm{N} / \mathrm{m}^{2}$

Figure 3: Longitude-time section (averaged between $2^{\circ} \mathrm{S}-2^{\circ} \mathrm{N}$ ) showing the mean seasonal cycle. Note that the first 3 months of the year are duplicated. a) TMI SST (years 1998-2009) in ${ }^{\circ} \mathrm{C}$ with ERA-Interim (years 1989-2009) surface wind stress vectors $\left(\mathrm{N} / \mathrm{m}^{2}\right)$ overlapped. Vector orientation follows the convention: eastward corresponds to the right side of the figure and northward to the upper side. $\mathrm{CI}=0.5^{\circ} \mathrm{C}$. b) same as a but for $24 \mathrm{~h} 31$ (years 11-110) SST and surface wind stress. c) Corresponds to b) minus a). $\mathrm{CI}=0.5^{\circ} \mathrm{C}$

Figure 4: Map of the annual mean amplitude of the SST diurnal cycle. a) 2h31 (years 11-110) and b) $2 \mathrm{~h} 301$ (years $11-75$ ). Units $={ }^{\circ} \mathrm{C}, \mathrm{CI}=0.1^{\circ} \mathrm{C}$

Figure 5: Maps of the difference of annual mean SST climatologies (years 11-110 for the 31 levels experiments and years 11-75 for the 301 levels experiments. a) $2 \mathrm{~h} 31-2 \mathrm{~h} 301$, b) $24 \mathrm{~h} 31$ $-24 \mathrm{~h} 301$, c) $2 \mathrm{~h} 31-24 \mathrm{~h} 31$, d) $2 \mathrm{~h} 301-24 \mathrm{~h} 301$. Units $={ }^{\circ} \mathrm{C}, \mathrm{CI}=0.2^{\circ} \mathrm{C}$

Figure 6: Longitude-time section (averaged between $2^{\circ} \mathrm{S}-2^{\circ} \mathrm{N}$ ) showing the difference of SST mean seasonal cycle between our four sensitivity experiments. a) $2 \mathrm{~h} 31-2 \mathrm{~h} 301$, b) $24 \mathrm{~h} 31$ $24 \mathrm{~h} 301$, c) $2 \mathrm{~h} 31-24 \mathrm{~h} 31$, d) $2 \mathrm{~h} 301-24 \mathrm{~h} 301$. Units $={ }^{\circ} \mathrm{C}, \mathrm{CI}=0.2^{\circ} \mathrm{C}$

Figure 7: Maps of the standard deviation of SST anomalies obtained trough STL filtering to remove the seasonal cycle and the long-term trends. a) HadISST1.1 (years 1950 - 2007) dataset (Rayner et al., 2003), b) 2h31 (years 11-110), c) 2h301 (years 11-75), d) 24h31 (years 11-110), e) $24 \mathrm{~h} 301$ (years $11-75$ ). Units $={ }^{\circ} \mathrm{C}, \mathrm{CI}=0.1^{\circ} \mathrm{C}$

Figure 8: Standard deviations of Niño3 (a) or Niño3.4 (b) SST time series computed over a 40 -years sliding window for $2 \mathrm{~h} 31$ in black, $24 \mathrm{~h} 31$ in blue, $2 \mathrm{~h} 301$ in orange and $24 \mathrm{~h} 301$ in green. Units $={ }^{\circ} \mathrm{C}$. c) Probability density function of Niño3.4 SST standard deviation estimated using a blockwise bootstrap procedure with a block length of 40-years from the four experiments. Units $={ }^{\circ} \mathrm{C}^{-1}$. Same color conventions as in a) and b).

Figure 9: Panels a and b: Power spectra of Niño3.4 SST anomalies for HadISST1.1 dataset (Rayner et al., 2003) in pink (a and b), $2 \mathrm{~h} 31$ in black (a), 24h31 in blue (a), 2h301 in green (b), 24h301 in orange (b). The bottom axis of each panel is the period (unit: year), the left axis 
is variance (unit: ${ }^{\circ} \mathrm{C}^{2}$ ) and both axes are in logarithm scale. Dashed curves show the pointwise $99 \%$ confidence limits for the Niño-34 SST spectrum estimated from the observations. Panel c: Logarithm of the ratio of the power spectra of the Niño3.4 SST for 2h31/24h31 on a logarithmic scale and point-wise 90\% confidence intervals (blue lines) for the logarithms of the spectral ratios for a postulated common spectrum in the two experiments. Panel c: same as b but for the $2 \mathrm{~h} 301 / 24 \mathrm{~h} 301$ experiments.

Figure 10: Maps of the logarithms of the ratio of the power spectra for each grid-point SST time series for $2 \mathrm{~h} 31 / 24 \mathrm{~h} 31$ ( $\mathrm{a}$ and b) and 2h301/24h301 (c and d) at specific periods: 72 (a and c) and 36 (b and d) months. Contours show the point-wise $90 \%$ confidence intervals for the logarithms of the spectral ratios at each specific period for a postulated common spectrum in the two experiments.

Figure 11: Maps of skewness for monthly SST anomalies. a) HadISST1.1 dataset (Rayner et al., 2003), b) $2 \mathrm{~h} 31$, c) $24 \mathrm{~h} 31$, d) $2 \mathrm{~h} 301$ and e) $24 \mathrm{~h} 301$. CI $=0.2$

Figure 12: Niño3.4 SST anomalies during individual El Niño (a and b) or La Niña (c and d) events (defined from Trenberth, 1997) in 2h31 (a and c) and 24h31 (b and d). Red (black) curves correspond to events peaking between October and March (April and September). Units $={ }^{\circ} \mathrm{C}$

Figure 13: Maps of the spatial patterns of the leading SST-SLP MCA modes for $2 \mathrm{~h} 31,24 \mathrm{~h} 31$, 2h301 and 24h301. Left column: SST homogeneous vectors in ${ }^{\circ} \mathrm{C}, \mathrm{CI}=0.1{ }^{\circ} \mathrm{C}$. Right column: SLP heterogeneous vectors $\mathrm{hPa}, \mathrm{CI}=0.1$ The maps were obtained by regressing the SLP and SST fields upon the normalized EC time series of SST. The SST and SLP fields are, respectively, homogenous and heterogeneous covariance patterns following the terminology of Bretherton et al. (1992). Summary statistics for these modes are given in Table 2.

Figure 14: Maps of the spatial patterns of the first leading MCA modes estimated for $2 \mathrm{~h} 31$. a) OLR heterogeneous covariance pattern corresponding to the leading mode of the SST-OLR MCA. CI $=1 \mathrm{~W} / \mathrm{m}^{2}$. b) Surface zonal wind stress heterogeneous covariance pattern corresponding to the leading mode of the SST-surface zonal wind stress MCA. CI $=0.2$ $\mathrm{N} / \mathrm{m} 2$. c) $0-300 \mathrm{~m}$ Heat Content heterogeneous covariance pattern corresponding to the leading mode of the surface zonal wind stress-Heat Content MCA. CI $=100 \mathrm{~W}$. d) Surface short wave radiation homogeneous covariance pattern corresponding to the leading mode of the short wave radiation-SST MCA. CI $=1 \mathrm{~W} / \mathrm{m}^{2}$. e) Latent heat flux homogeneous covariance pattern corresponding to the leading mode of the latent heat flux-SST MCA. CI $=1 \mathrm{~W} / \mathrm{m}^{2} . \mathrm{f}$ ), g), $\mathrm{h}$ ), i) and j) same as a), b), c), d) and e), respectively, but for the first leading MCA modes estimated for $24 \mathrm{~h} 31$. 


\section{Table captions:}

Table 1: Summary of the numerical experiments with their main characteristics, including length, horizontal and vertical resolutions and frequency of coupling for the different air-sea fluxes.

Table 2 Summary statistics for the SST-SLP MCA leading modes estimated from the four experiments, including the SCFs and NCs for the leading modes in the various MCA expansions and the correlation $(r)$ between the EC time series of the left and right fields. As discussed by Zhang et al. (1998), the NC and $r$ coefficients are particularly useful in comparing the strength of the coupling between the left and right fields in modes obtained from different MCAs. SLPvar and SSTvar are, respectively, SLP and SST variances accounted for by the leading mode of each MCA analysis (e.g. this is the variance of the field explained by the related Expansion Coefficient time series by linear regression). The correlation coefficients (at zero lag) between the leading SST EC time series and the Niño34 SST time series in each experiment are also given in the last column.

Table 3: Same as Table 2, but for the SST-zonal wind stress and SST-OLR MCA leading modes from the four experiments.

Table 4: Same as Table 2, but for the zonal wind stress-HC MCA leading modes estimated from the four experiments. The maximum correlation coefficients at any lag between the leading HC EC time series and the Niño34 SST time series in each experiment are also given in the last column and the lag (in months) which maximizes the correlation is given in brackets. The lag is negative when the Niño34 SST time series leads the first SST EC time series in each experiment.

Table 5: Same as Table 2, but for the SST-SWR and SST-LHF MCA leading modes estimated from the four experiments. 
Tables

Table 1

\begin{tabular}{|c|c|c|c|c|}
\hline Experiment name & $\mathbf{2 h 3 1}$ & $\mathbf{2 4 h 3 1}$ & $\mathbf{2 h 3 0 1}$ & $\mathbf{2 4 h 3 0 1}$ \\
\hline Oceanic vertical resolution & $31(10 \mathrm{~m})$ & $31(10 \mathrm{~m})$ & $301(1 \mathrm{~m})$ & $301(1 \mathrm{~m})$ \\
\hline SST coupling frequency & $2 \mathrm{~h}$ & $24 \mathrm{~h}$ & $2 \mathrm{~h}$ & $24 \mathrm{~h}$ \\
\hline Other data coupling frequency & $2 \mathrm{~h}$ & $2 \mathrm{~h}$ & $2 \mathrm{~h}$ & $2 \mathrm{~h}$ \\
\hline Experience length (in years) & 110 & 110 & 75 & 75 \\
\hline
\end{tabular}

Table 2

SST - SLP MCAs

\begin{tabular}{|c|c|c|c|c|c|c|}
\hline SVD1 & SCF (\%) & NC (\%) & r & SSTvar (\%) & SLPvar(\%) & Corr Nino34 \\
\hline $2 \mathrm{~h} 31$ & 70 & 11 & 0.78 & 20.7 & 9.5 & 0.95 \\
\hline $24 \mathrm{~h} 31$ & 58 & 7 & 0.68 & 14.9 & 8.4 & 0.94 \\
\hline $2 \mathrm{~h} 301$ & 58 & 9 & 0.76 & 16 & 8.7 & 0.94 \\
\hline $24 \mathrm{~h} 301$ & 41 & 6 & 0.70 & 11.2 & 7.6 & 0.91 \\
\hline
\end{tabular}

Table 3

$\underline{\text { SST - zonal wind stress (U) MCAs }}$

\begin{tabular}{|c|c|c|c|c|c|}
\hline SVD1 & SCF (\%) & NC (\%) & r & SSTvar (\%) & Uvar(\%) \\
\hline $2 \mathrm{~h} 31$ & 61 & 7.3 & 0.57 & 20.8 & 7.9 \\
\hline $24 \mathrm{~h} 31$ & 45 & 5 & 0.48 & 15.2 & 7.5 \\
\hline $2 \mathrm{~h} 301$ & 46 & 6 & 0.53 & 15.8 & 7.6 \\
\hline $24 \mathrm{~h} 301$ & 29 & 4 & 0.50 & 10.5 & 6 \\
\hline
\end{tabular}

\section{SST - OLR MCAs}

\begin{tabular}{|c|c|c|c|c|c|}
\hline SVD1 & SCF (\%) & NC (\%) & r & SSTvar (\%) & OLRvar(\%) \\
\hline $2 \mathrm{~h} 31$ & 85 & 15 & 0.85 & 21.3 & 14.7 \\
\hline $24 \mathrm{~h} 31$ & 76 & 10 & 0.81 & 15.4 & 11.2 \\
\hline $2 \mathrm{~h} 301$ & 74 & 12 & 0.84 & 16.5 & 12.9 \\
\hline $24 \mathrm{~h} 301$ & 66 & 9 & 0.83 & 11.5 & 11.7 \\
\hline
\end{tabular}


Table 4

$\underline{\text { zonal wind stress }(\mathrm{U}) \text { - 0-300 } \mathrm{m} \text { heat content (HC) MCAs }}$

\begin{tabular}{|c|c|c|c|c|c|c|}
\hline SVD1 & SCF (\%) & NC (\%) & r & Uvar(\%) & HCvar (\%) & Corr Nino34 \\
\hline $2 \mathrm{~h} 31$ & 69 & 8.2 & 0.6 & 7.1 & 26.7 & $0.87(-1)$ \\
\hline $24 \mathrm{~h} 31$ & 54 & 5 & 0.54 & 5 & 19.9 & $0.79(0)$ \\
\hline $2 \mathrm{~h} 301$ & 53 & 6 & 0.53 & 7.9 & 16.8 & $0.81(-2)$ \\
\hline $24 \mathrm{~h} 301$ & 44 & 4.9 & 0.55 & 5 & 16 & $0.82(0)$ \\
\hline
\end{tabular}

Table 5

$\underline{\text { SST - short wave radiation (SWR) MCAs }}$

\begin{tabular}{|c|c|c|c|c|c|}
\hline SVD1 & SCF (\%) & NC (\%) & r & SSTvar (\%) & SWRvar(\%) \\
\hline $2 \mathrm{~h} 31$ & 78 & 10.6 & 0.84 & 20.7 & 7.8 \\
\hline $24 \mathrm{~h} 31$ & 66 & 7.5 & 0.8 & 14.9 & 5.9 \\
\hline $2 \mathrm{~h} 301$ & 67 & 9 & 0.83 & 16.6 & 7.4 \\
\hline $24 \mathrm{~h} 301$ & 54 & 6.9 & 0.82 & 11.3 & 6.2 \\
\hline
\end{tabular}

SST - latent heat flux (LHF) MCAs

\begin{tabular}{|c|c|c|c|c|c|}
\hline SVD1 & SCF (\%) & NC (\%) & r & SSTvar (\%) & LHFvar(\%) \\
\hline $2 \mathrm{~h} 31$ & 70 & 7 & 0.79 & 21 & 3.8 \\
\hline $24 \mathrm{~h} 31$ & 55.8 & 4.8 & 0.74 & 15 & 2.9 \\
\hline $2 \mathrm{~h} 301$ & 52.9 & 5.3 & 0.74 & 16 & 3.2 \\
\hline $24 \mathrm{~h} 301$ & 40.9 & 4.1 & 0.72 & 11.3 & 3 \\
\hline
\end{tabular}


a) SST: 2 h31 (yrs: 11-110)

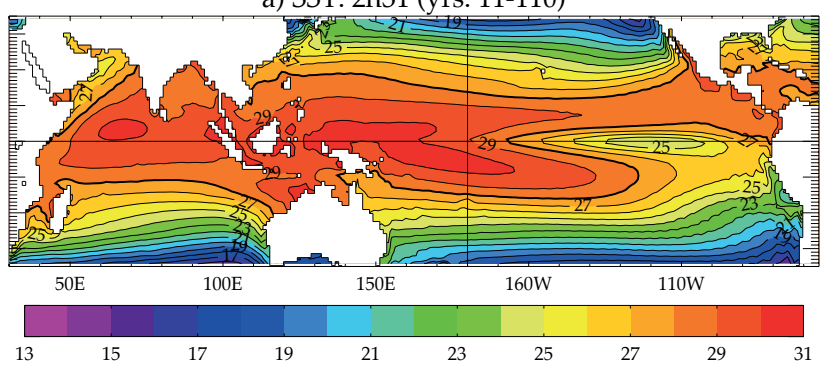

c) Precip: 2 h31 (yrs: 11-110)

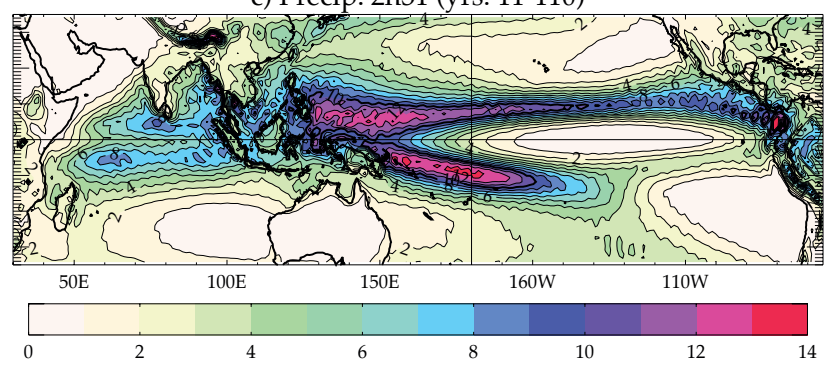

e) Wind stress: $2 \mathrm{~h} 31$ (yrs: 11-110)

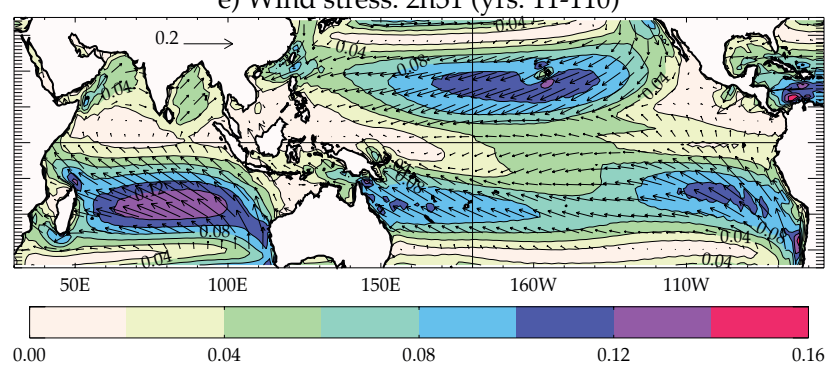

b) SST: 2 h31 (yrs: 11-110) - TMI (yrs: 1998-2009)

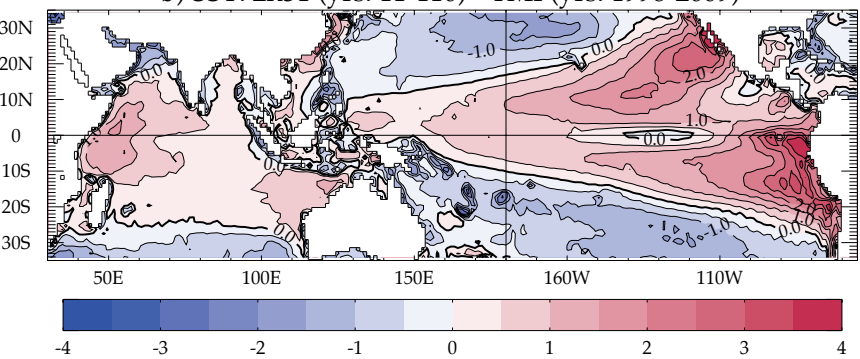

d) Precip: 2 h31 (yrs: 11-110) - CMAP (yrs: 1979-2009)

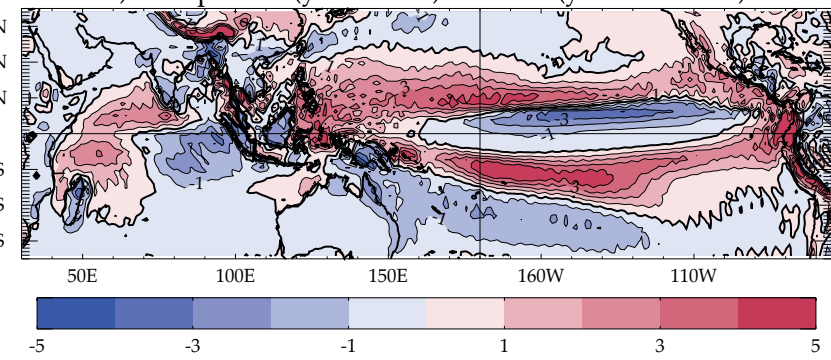

f) Wind stress: 2h31 (yrs: 11-110) - ERA-interim (yrs: 1989-2009)

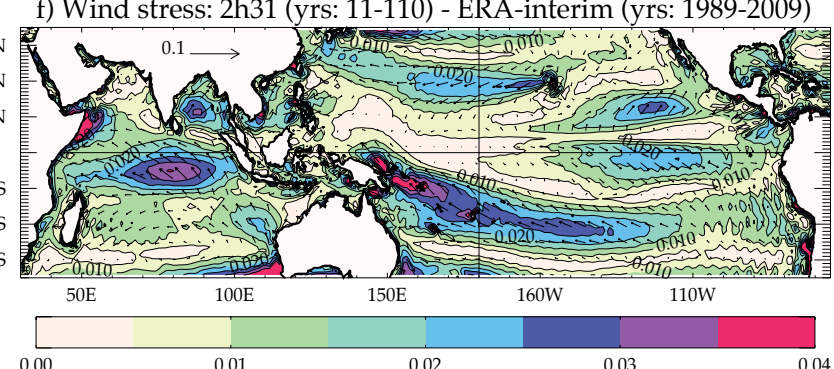




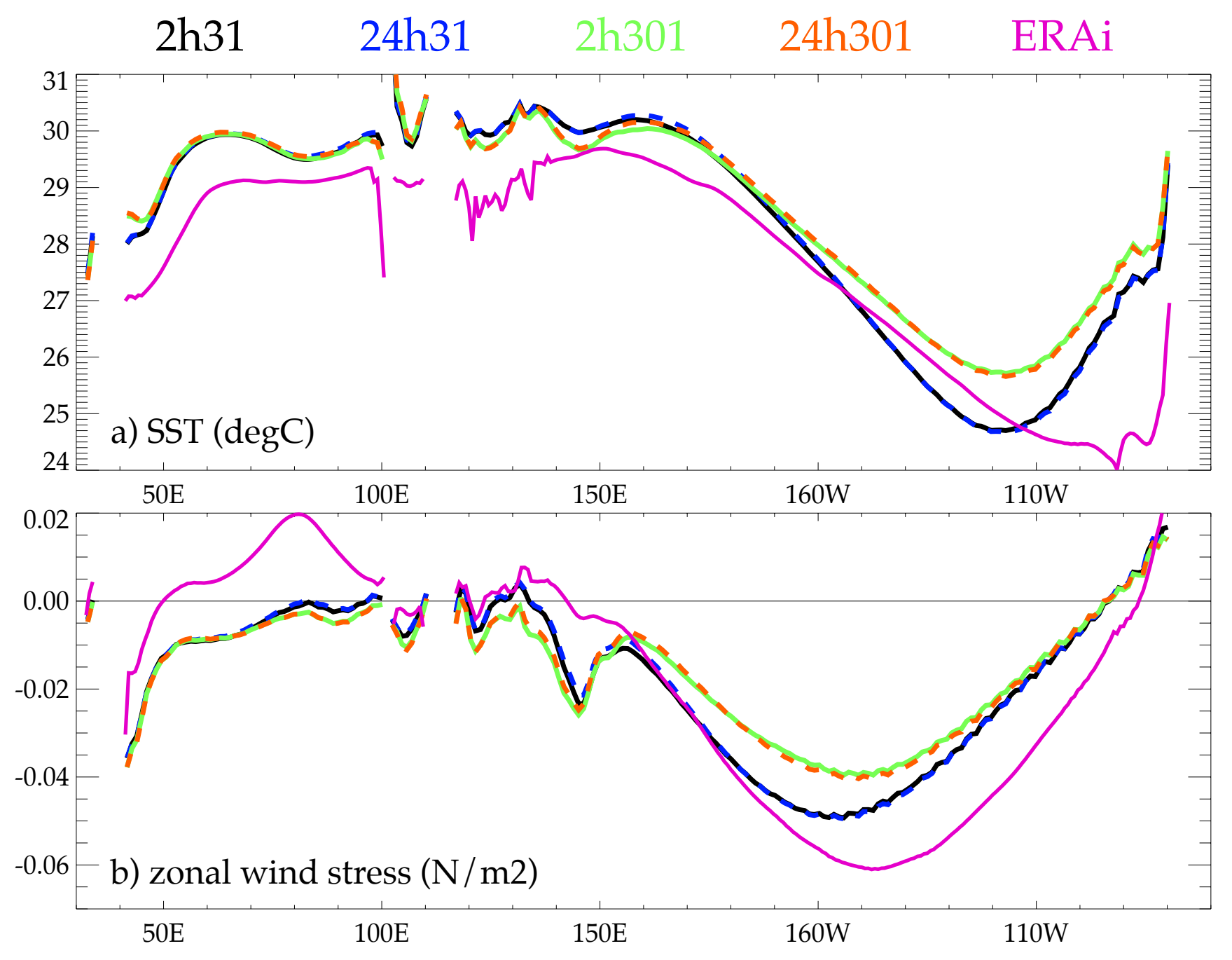

Fig. 2 
a) TMI (yrs: 1998-2009)

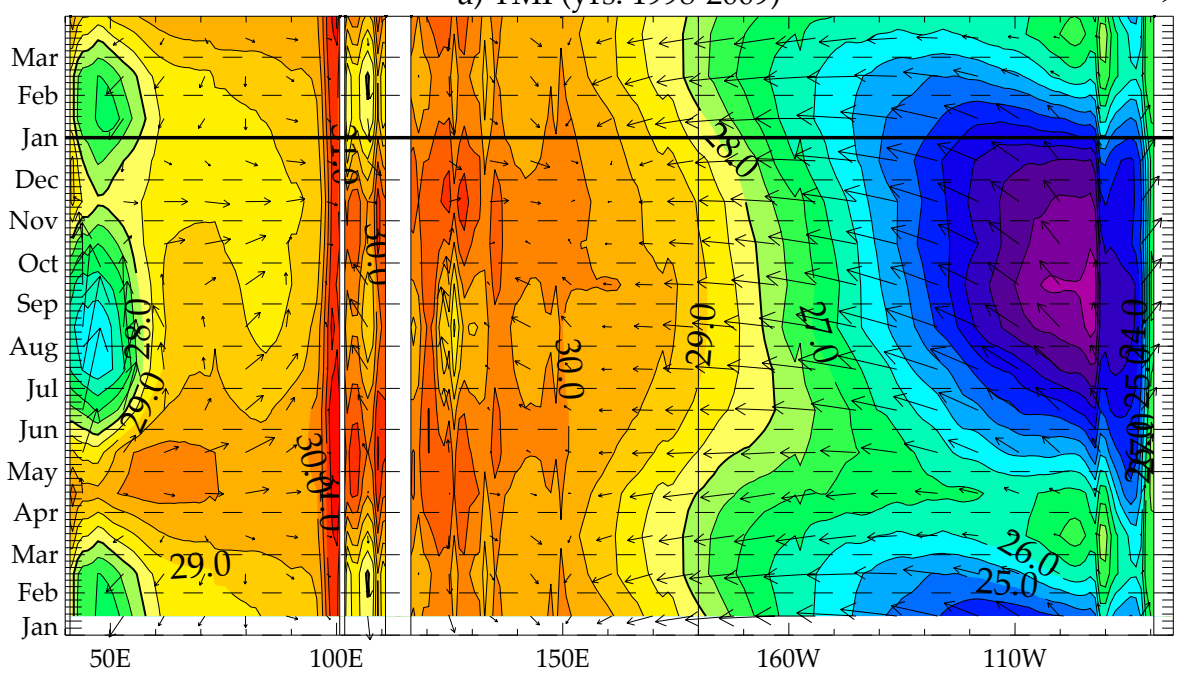

b) 2h31 (yrs: 11-110)

$0.05 \longrightarrow$
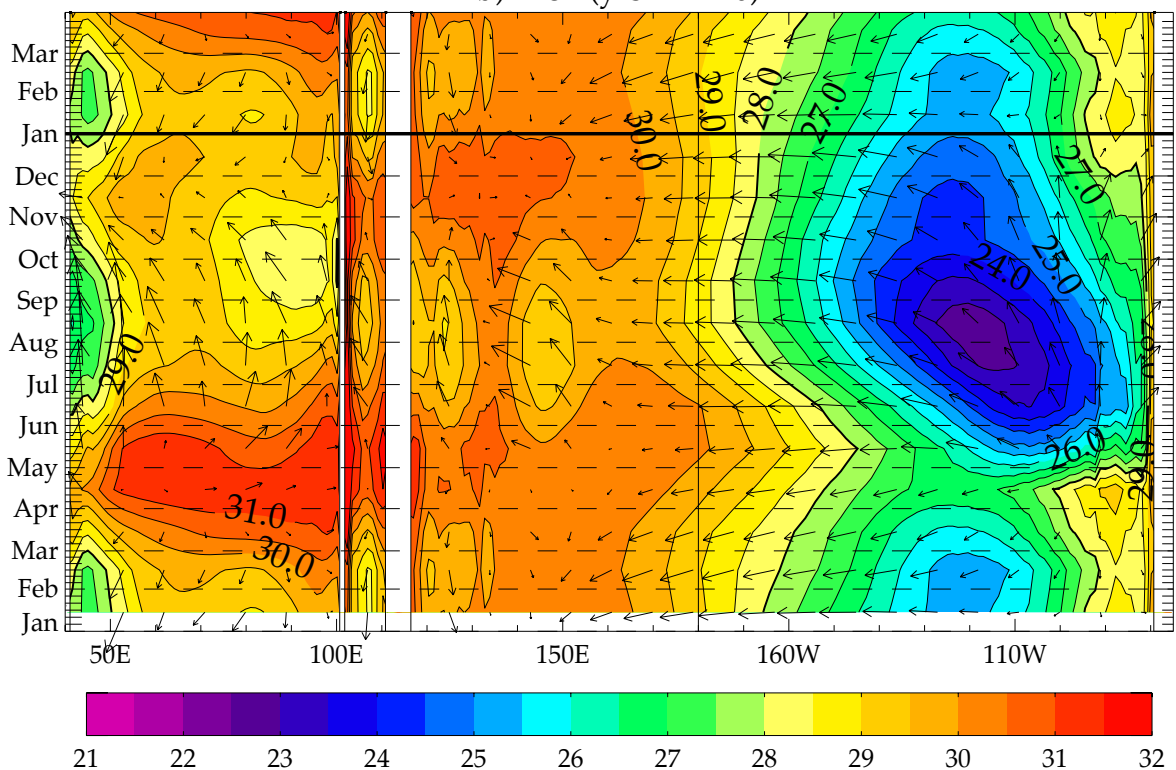

c) 2h31 (yrs: 11-110) - TMI (yrs: 1998-2009) $0.05 \longrightarrow$

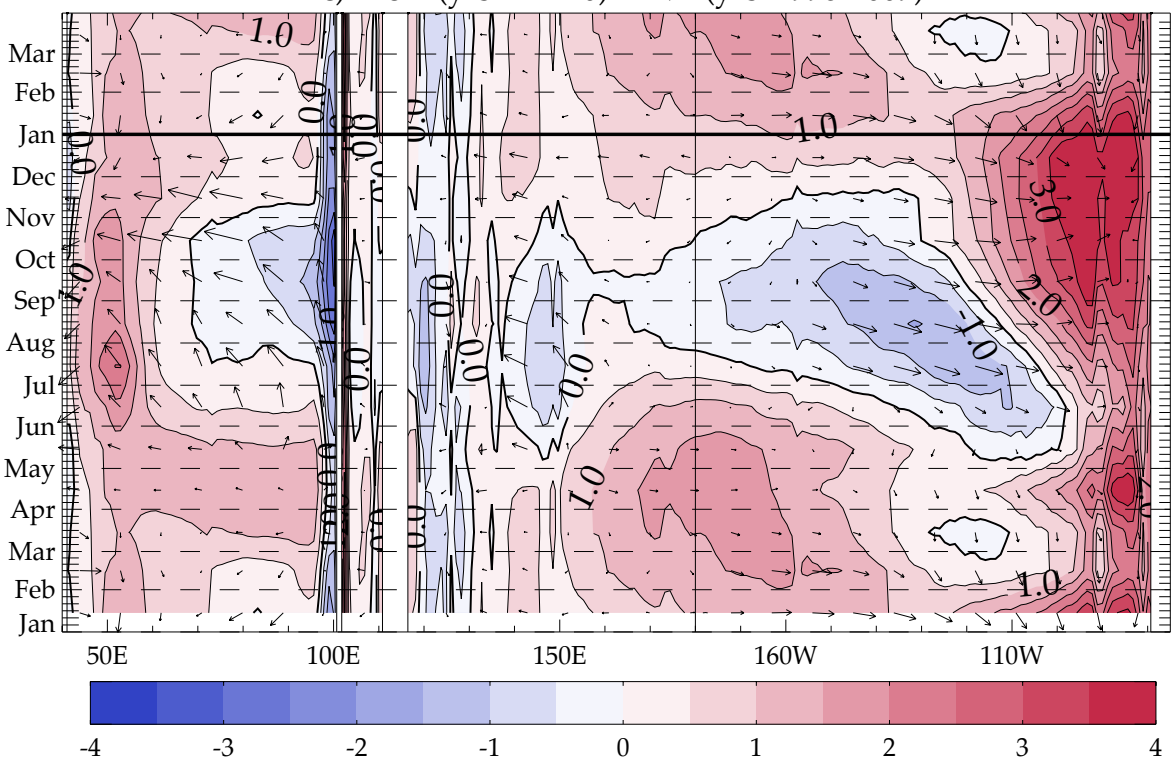

Fig. 3 

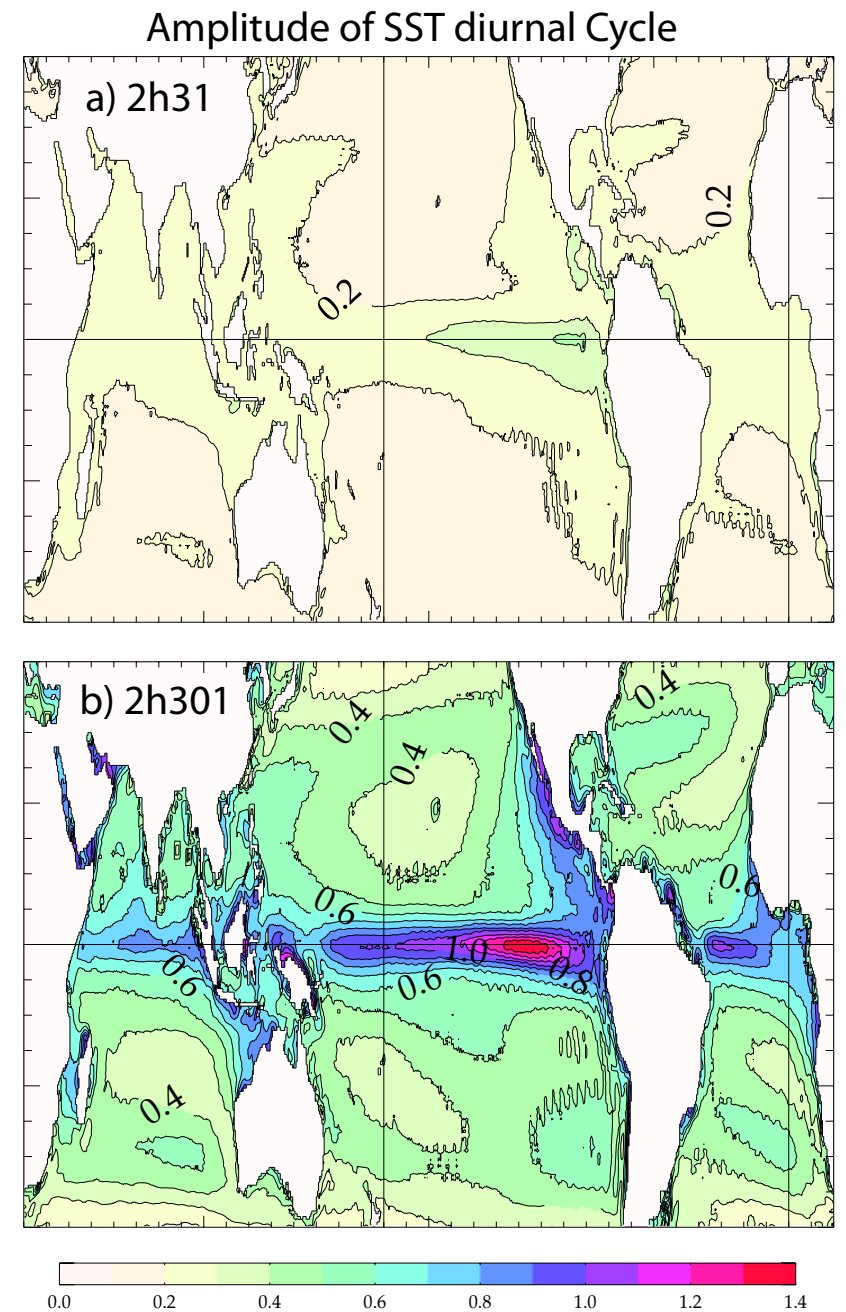

Fig. 4 

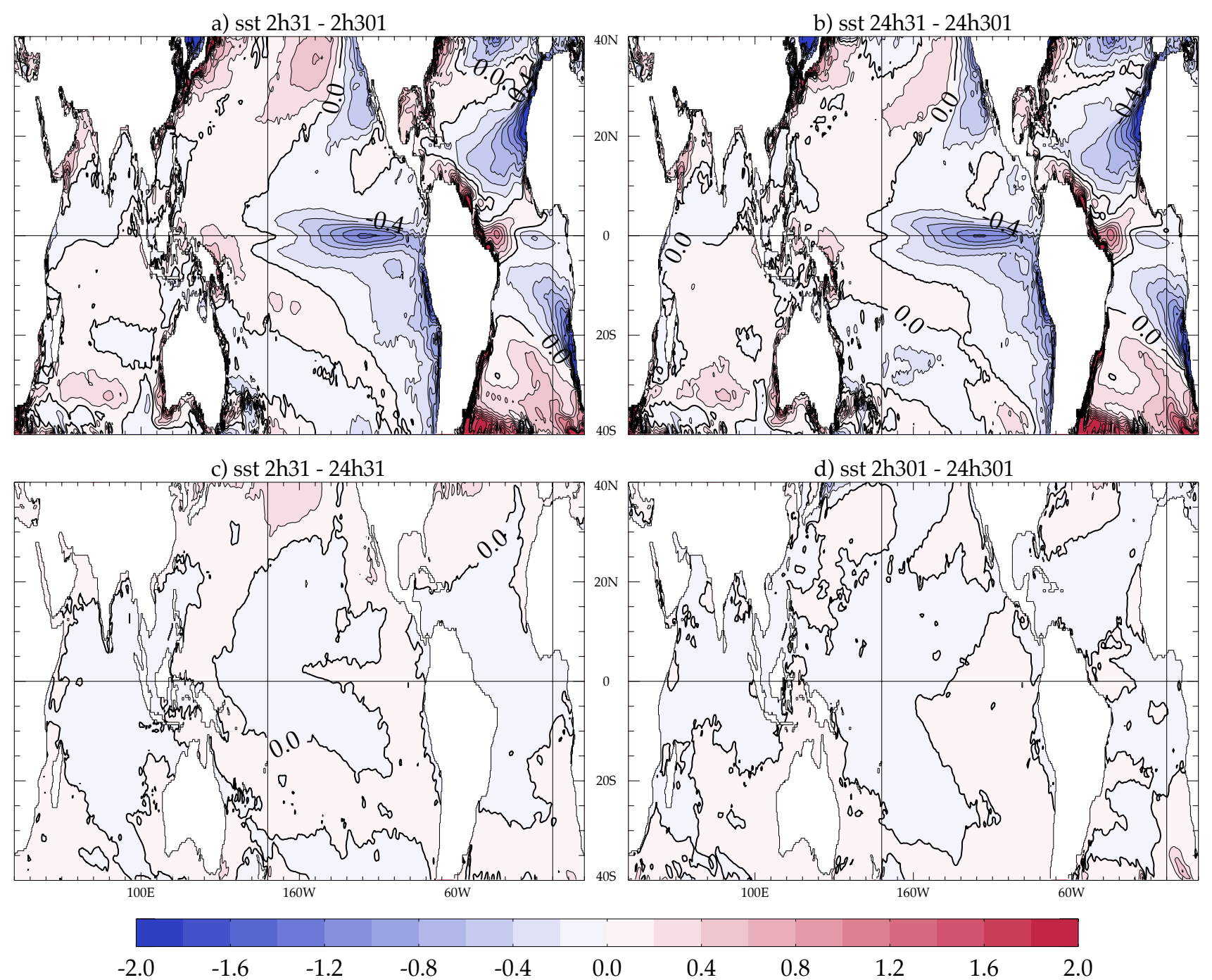

Fig. 5 

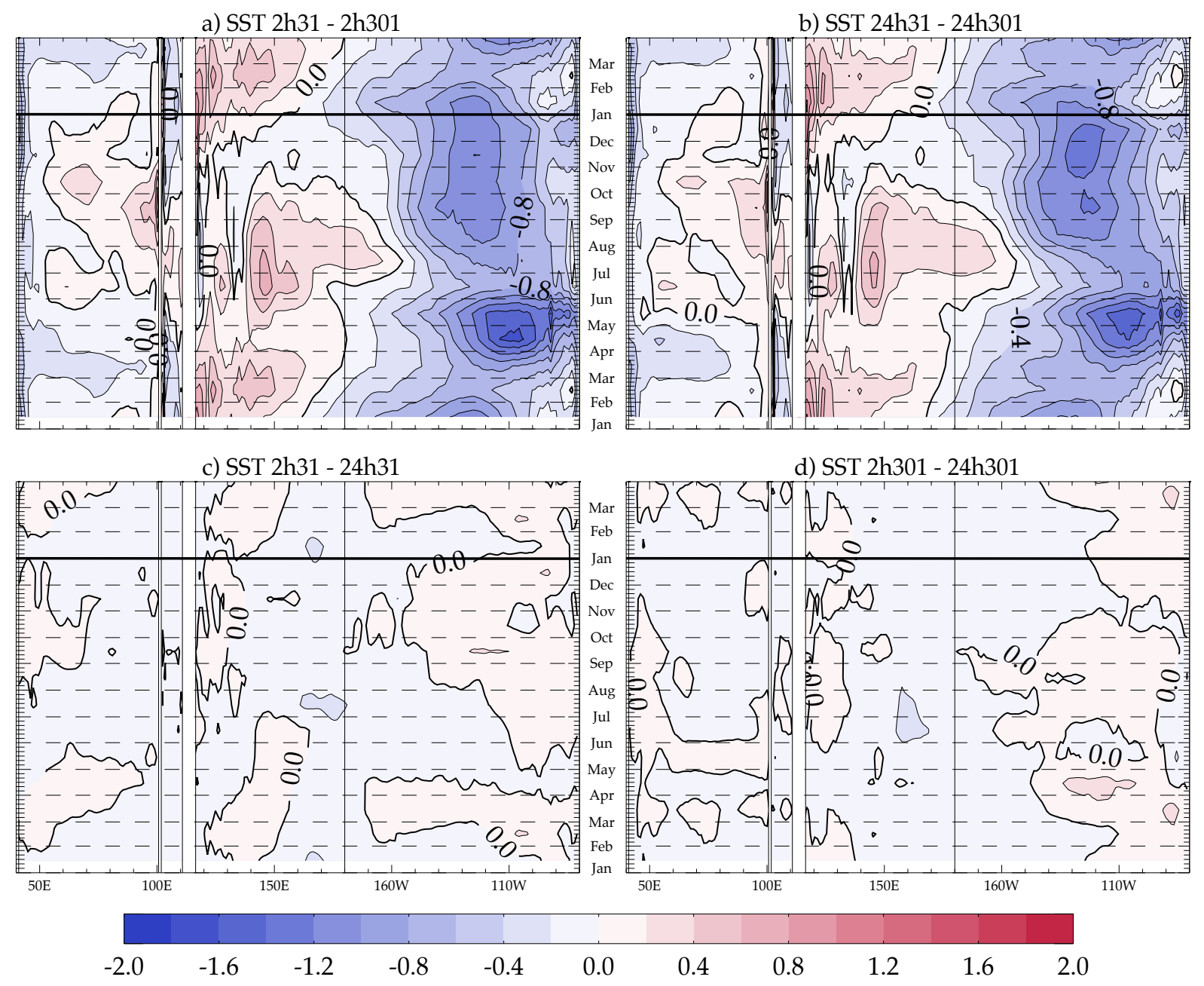

Fig. 6 


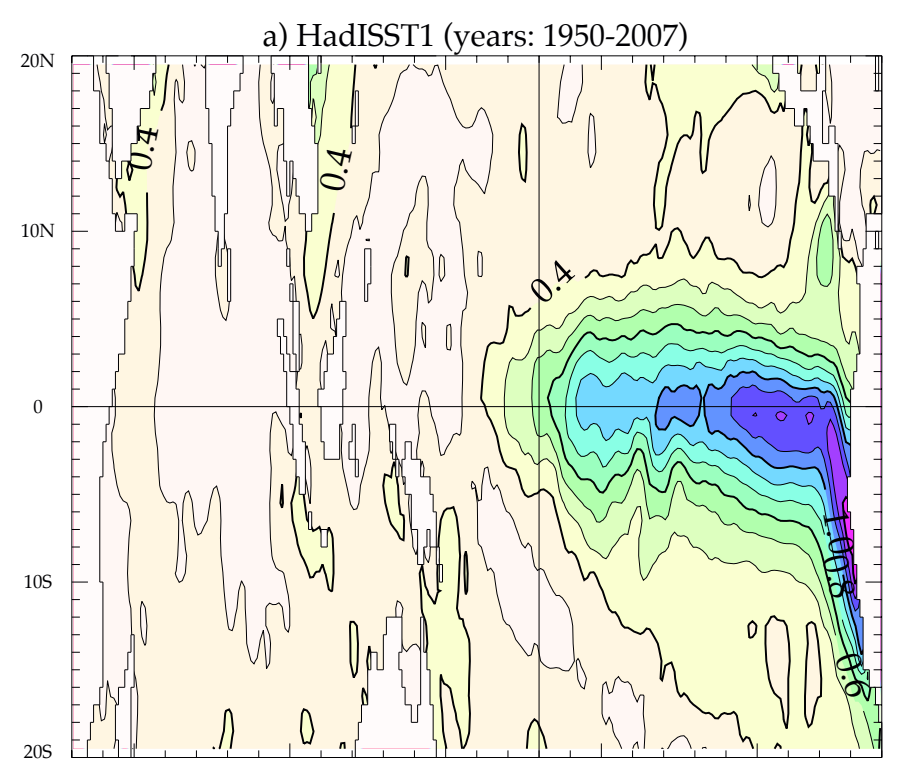

b) 2h31 (years: 11-110)
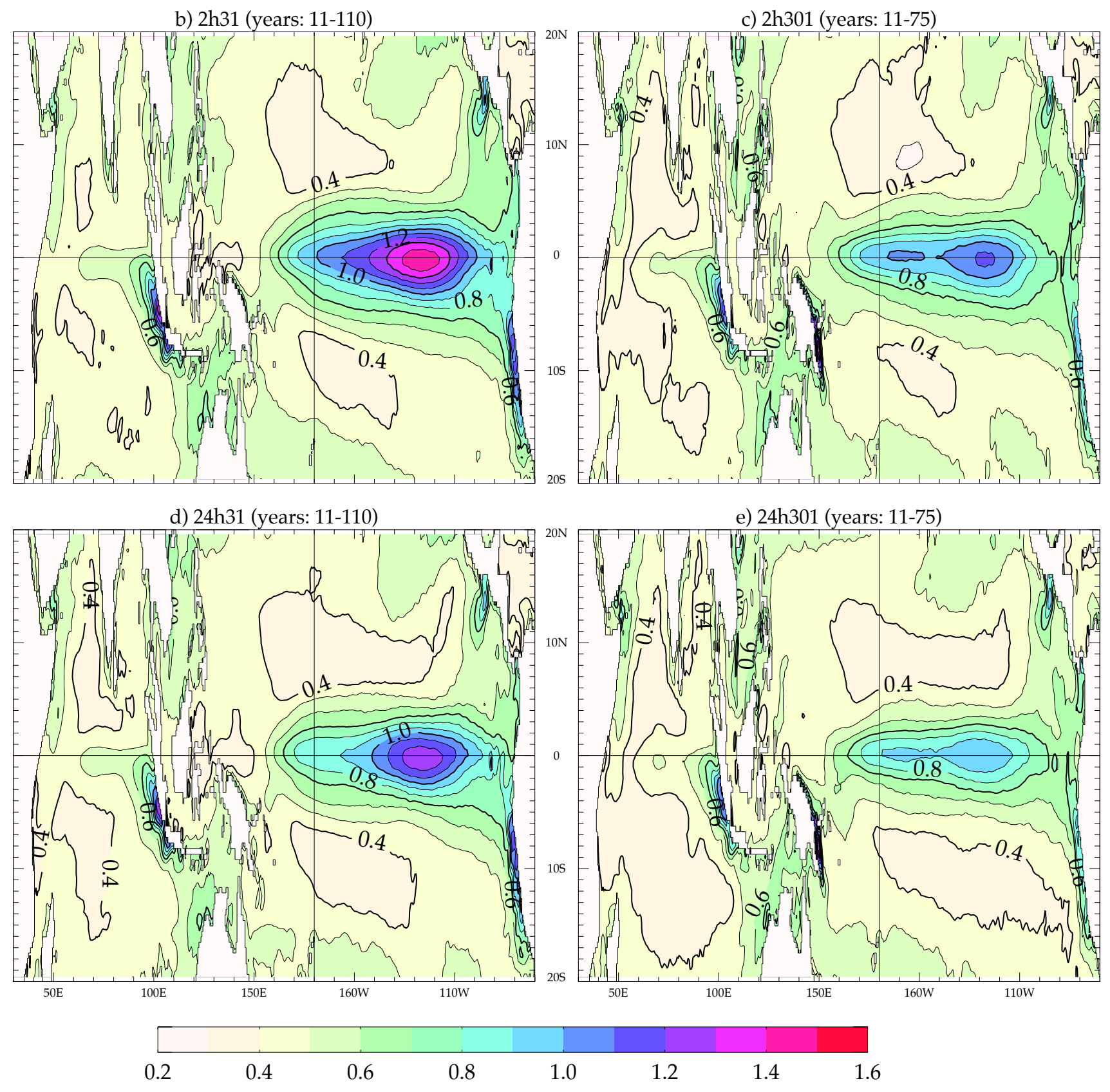

Fig. 7 
a) Nino3 SST sliding StdDev (window $=40 \mathrm{yrs)}$

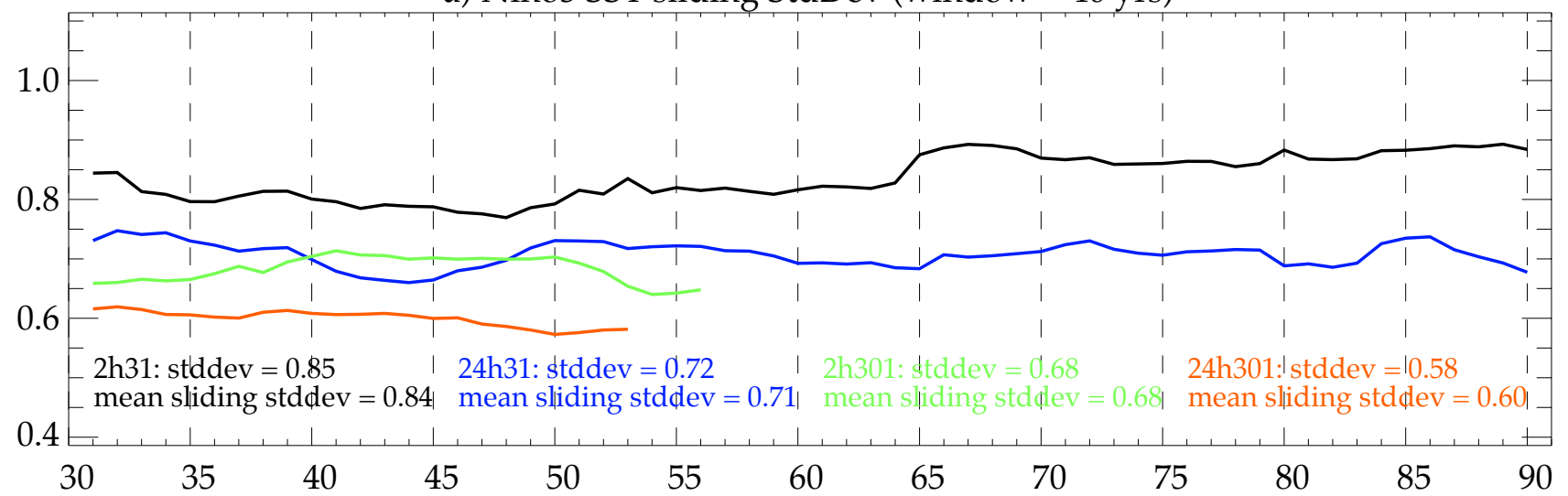

b) Nino3.4 SST sliding StdDev (window $=40$ yrs)

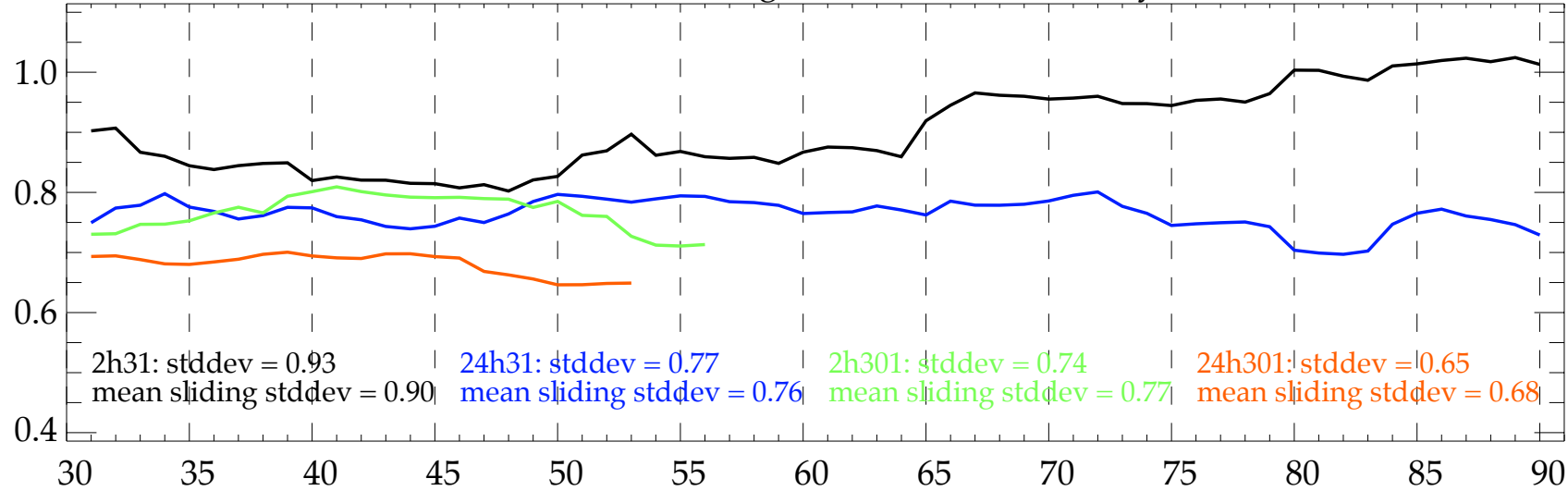

c) Standard Deviation of Nino3.4 SST (40 year-long window)

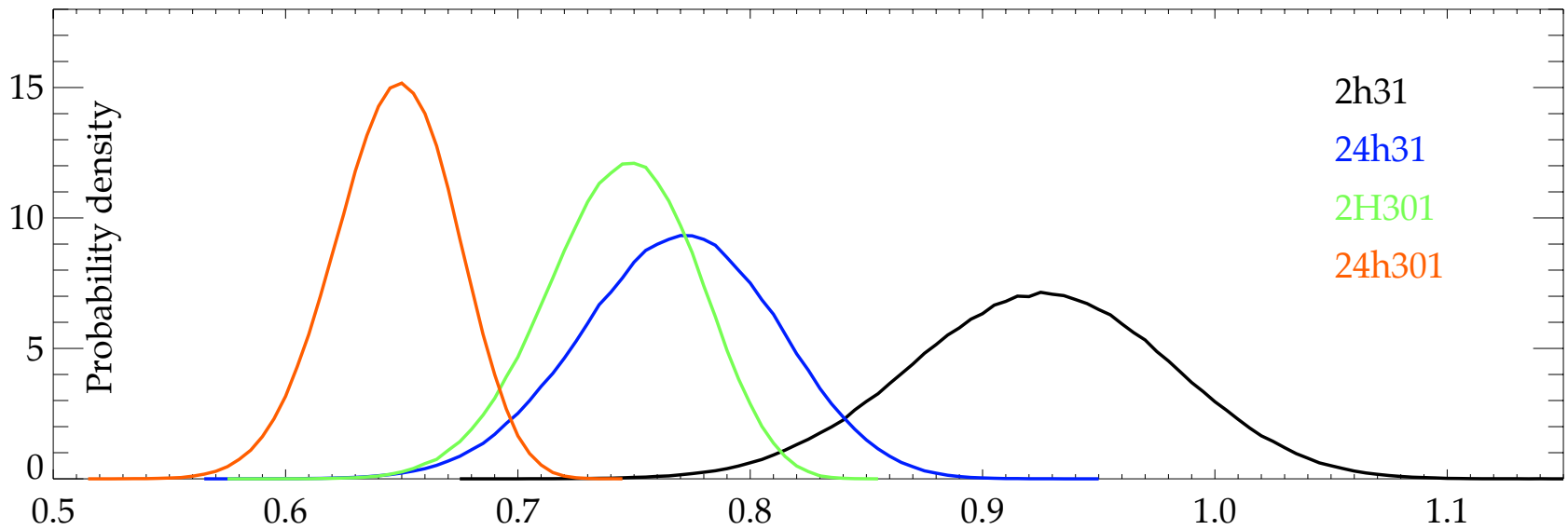

Fig. 8 


\section{SST Nino34 power spectrum}

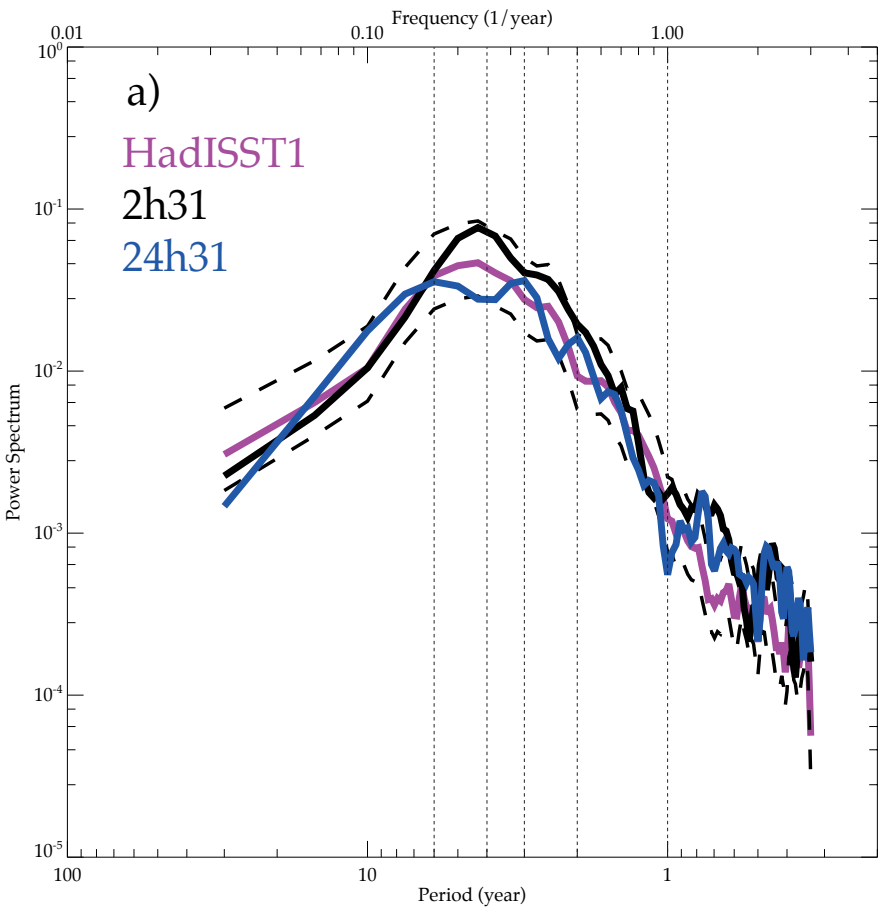

2h31/24h31 log spectral ratio
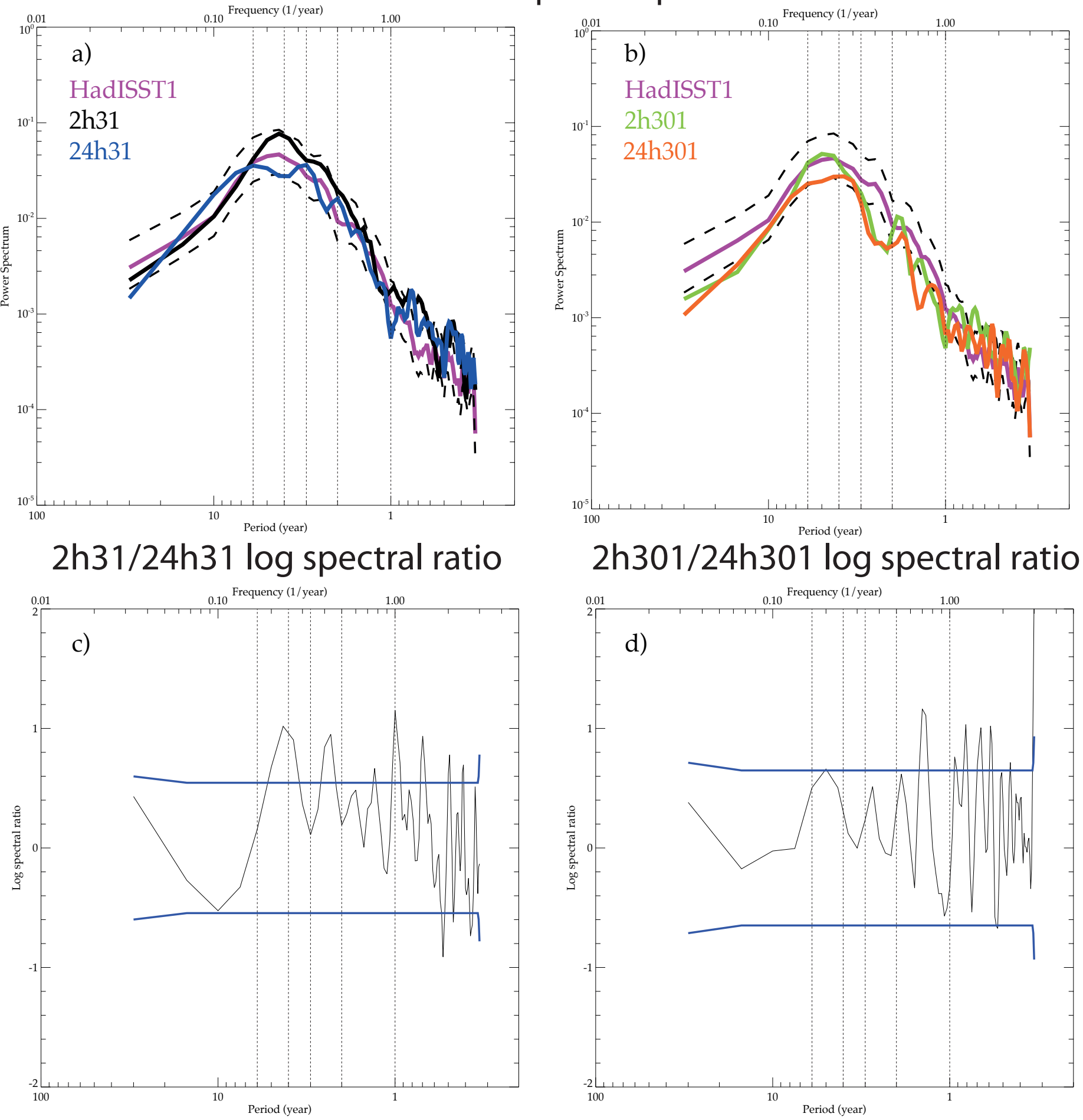

Fig. 9 

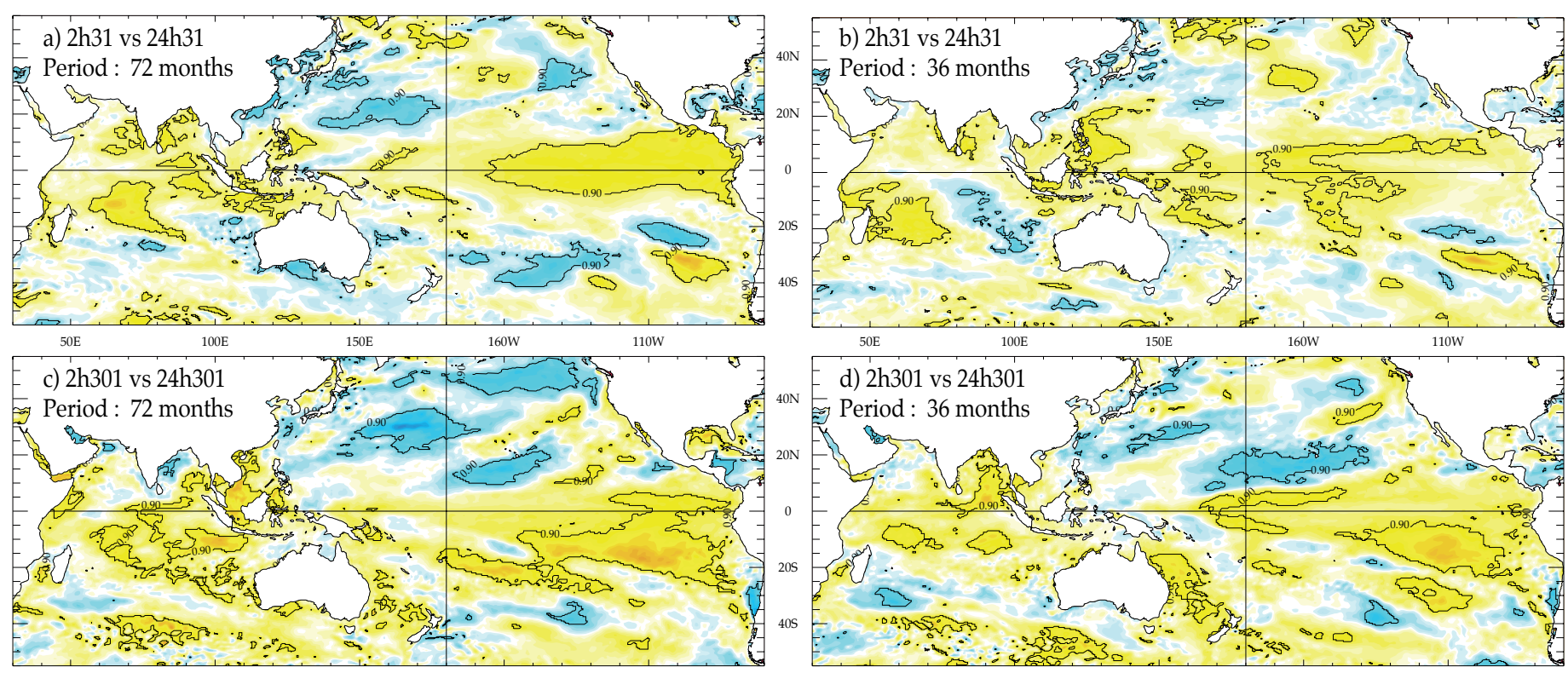

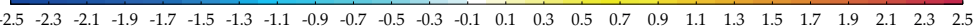



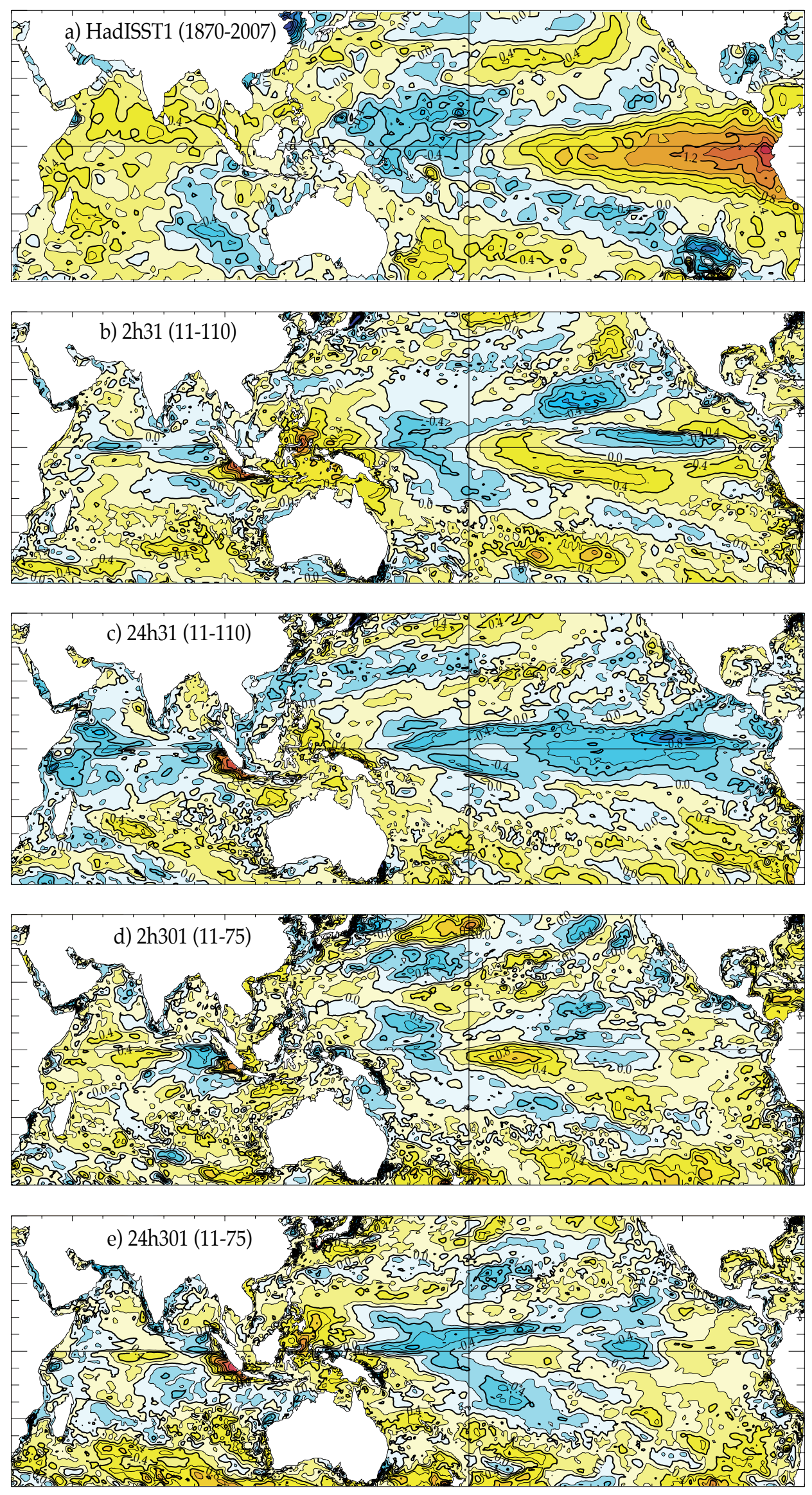
a) 2h31: 16 El Nino events (0011-0110)

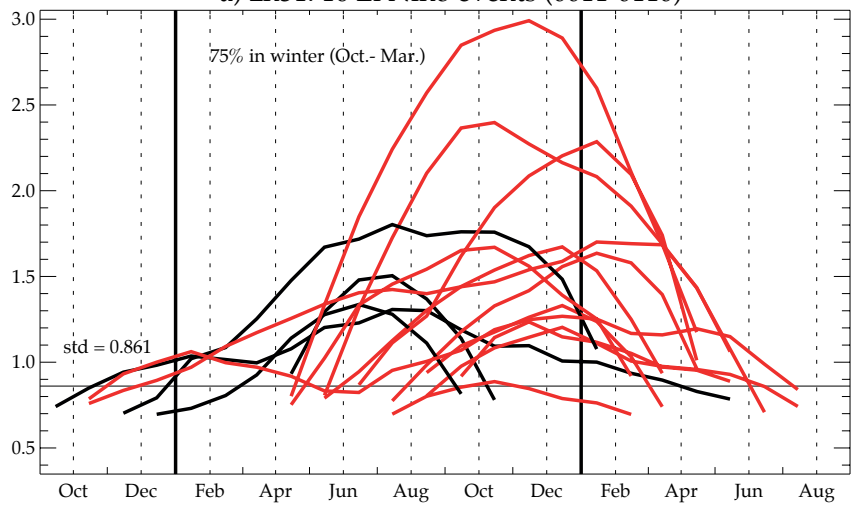

c) 2h31: 24 La Nina events (0011-0110)

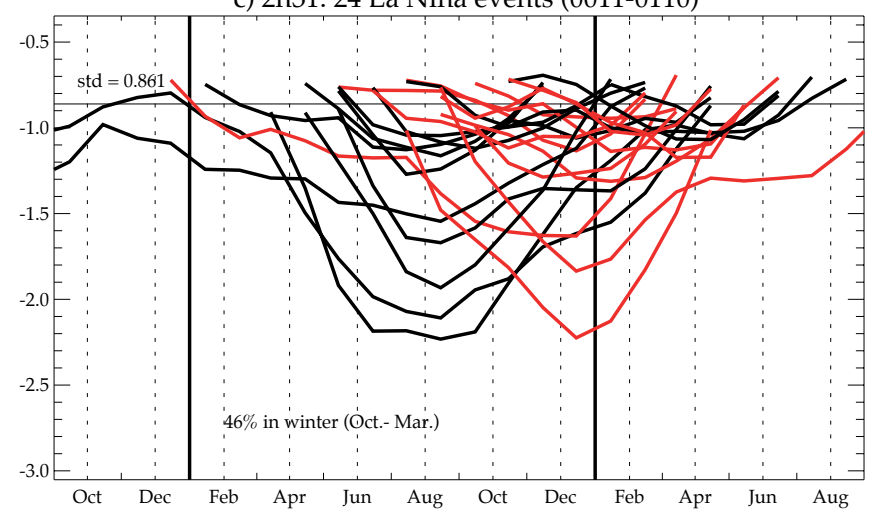

b) 24h31: 23 El Nino events (0011-0110)

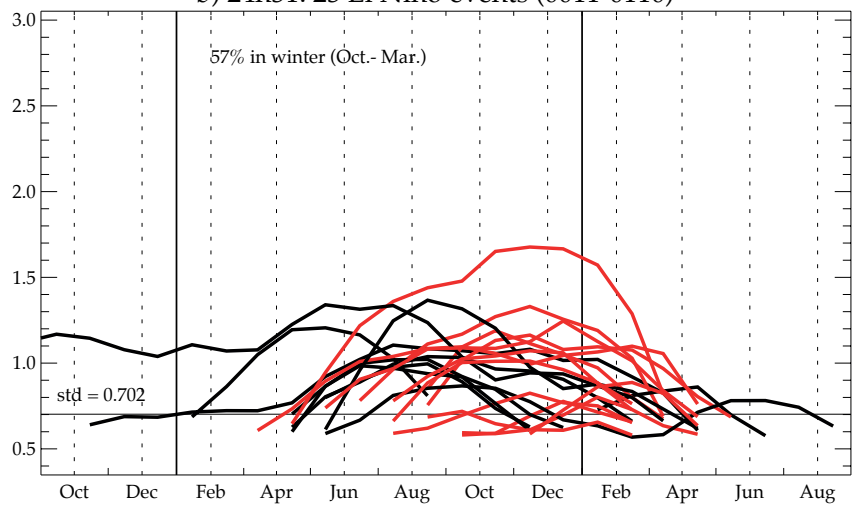

d) 24h31: 20 La Nina events (0011-0110)

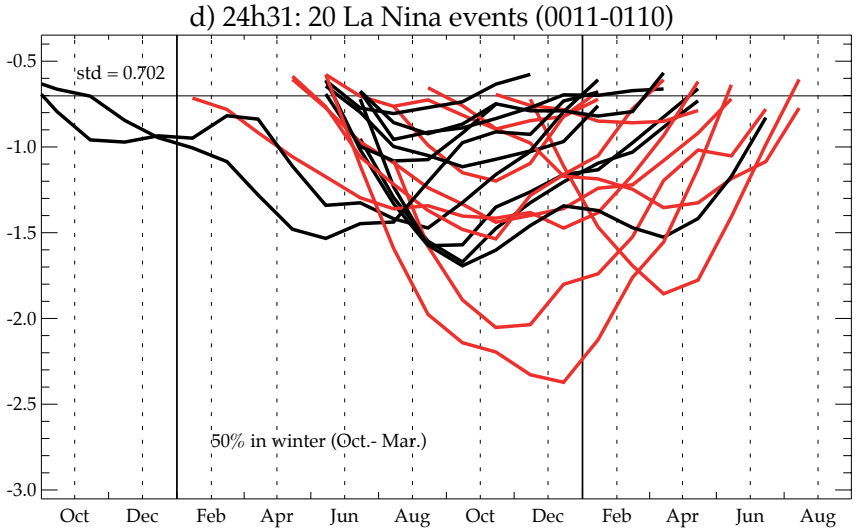



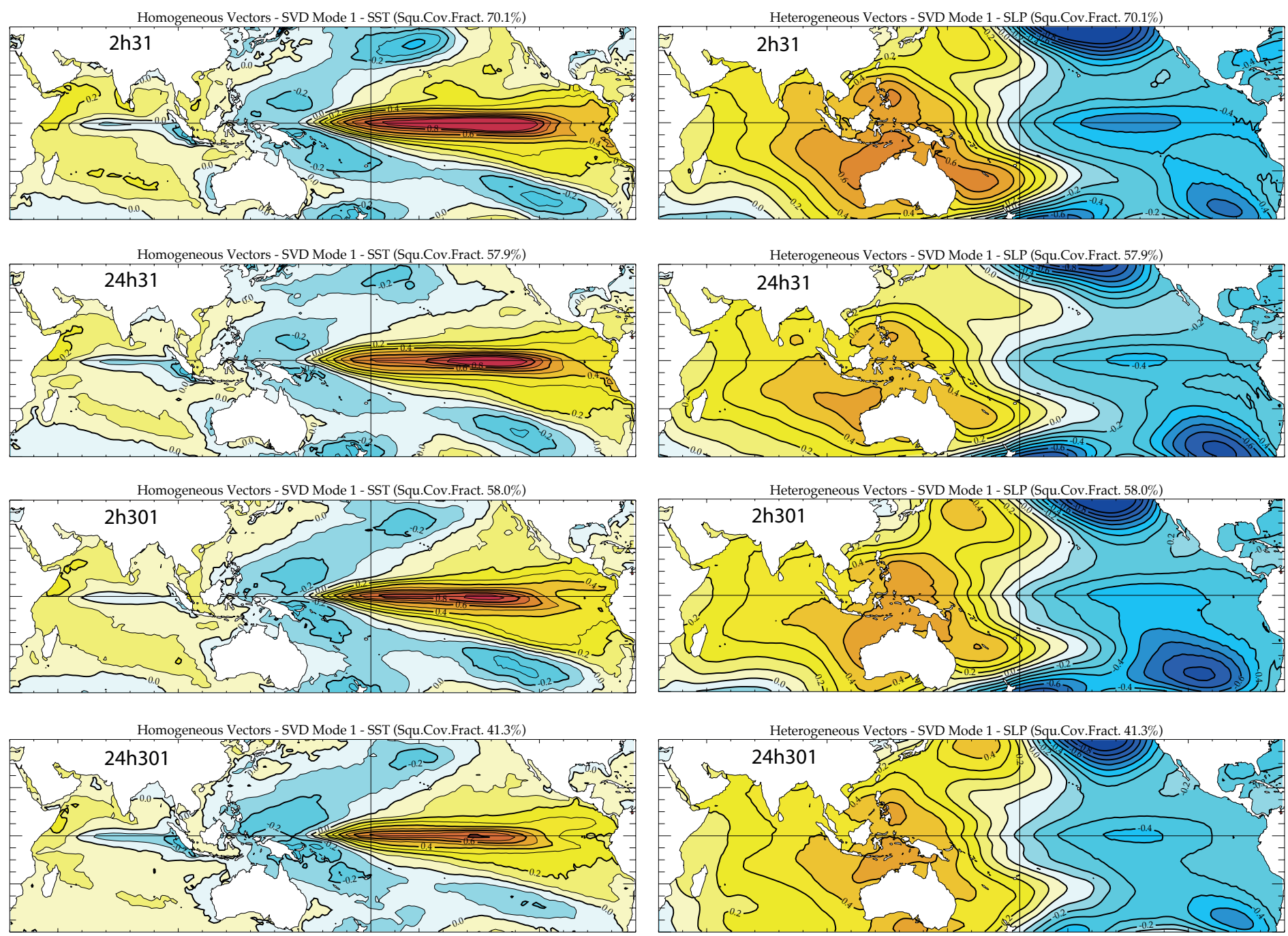
a) 2h31, SST / OLR MCA

OLR heterogeneous Vector - SVD Mode 1 (Squ.Cov.Fract. 85.2\%)

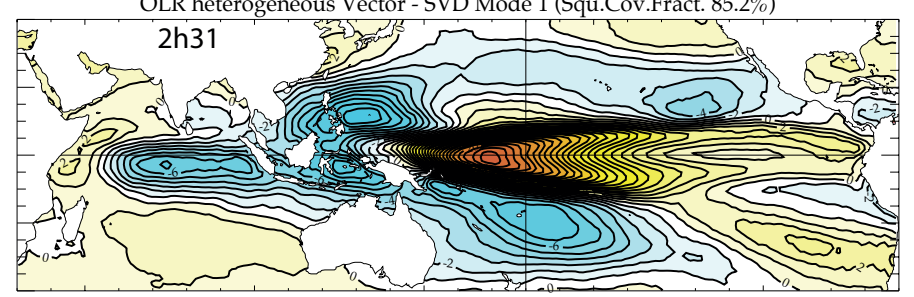

b) 2 h31, SST / zonal wind stress MCA

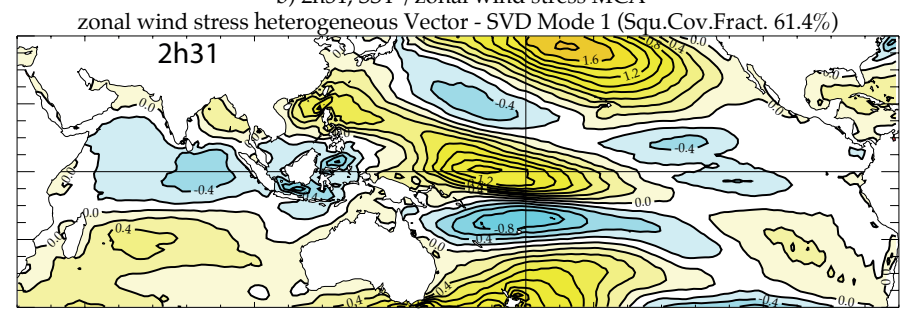

c) $2 \mathrm{~h} 31$, zonal wind stress / heat contain MCA

Heat contain heterogeneous Vector - SVD Mode 1 (Squ.Cov.Fract. 69.3\%)

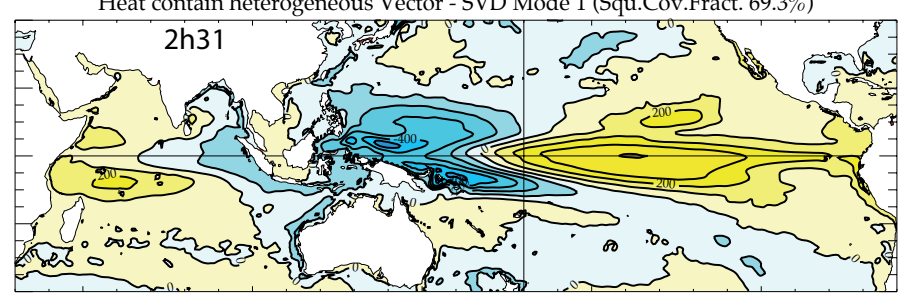

d) 2 h31, short wave radiation / SST MCA

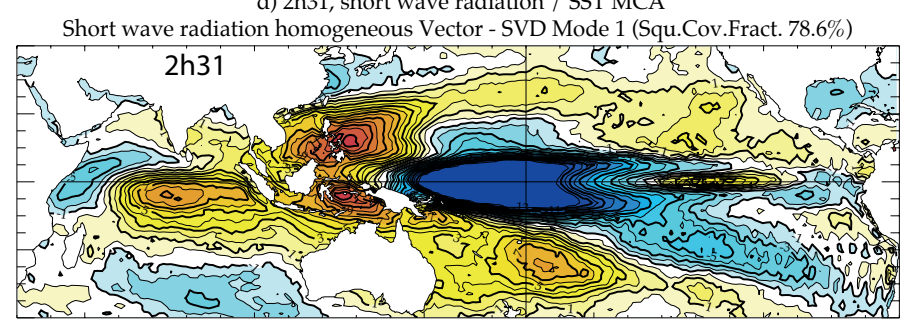

e) $2 \mathrm{~h} 31$, latent heat flux / SST MCA

Latent heat flux homogeneous Vector - SVD Mode 1 (Squ Cov.Fract. 70.1\%)

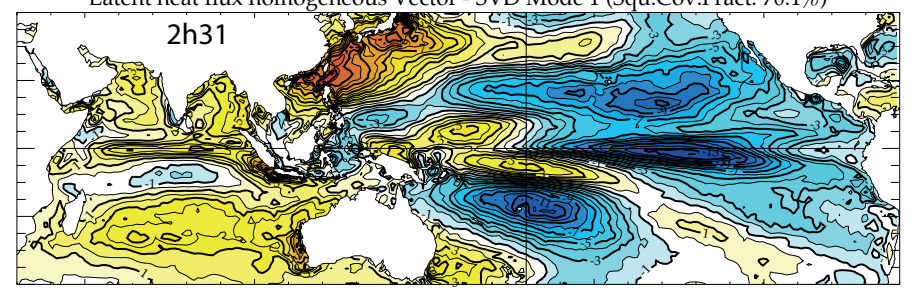

f) $24 \mathrm{~h} 31$, SST / OLR MCA

OLR heterogeneous Vector - SVD Mode 1 (Squ.Cov.Fract. 75.8\%)

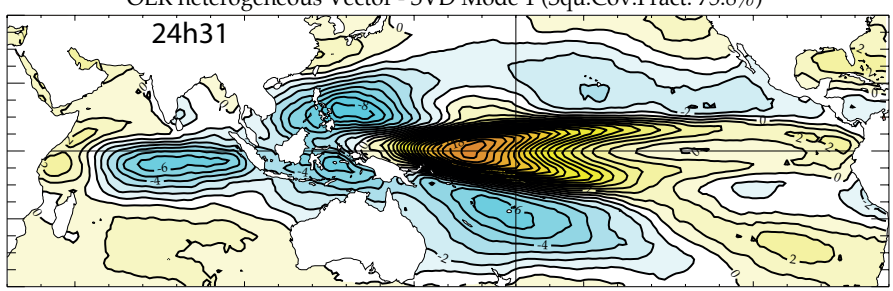

g) 24h31, SST / zonal wind stress MCA

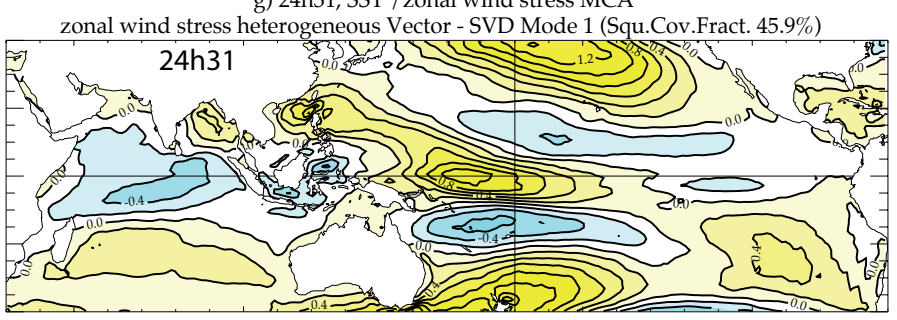

h) 24h31, zonal wind stress / heat contain MCA

Heat contain heterogeneous Vector - SVD Mode 1 (Squ.Cov.Fract. 53.8\%)

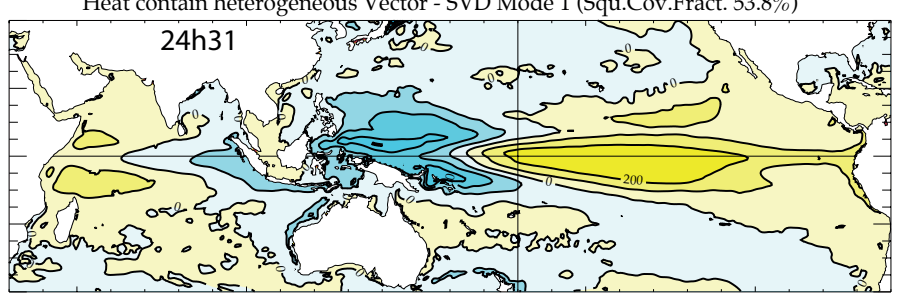

i) $24 \mathrm{~h} 31$, short wave radiation / SST MCA

Short wave radiation homogeneous Vector - SVD Mode 1 (Squ.Cov.Fract. 66.3\%)

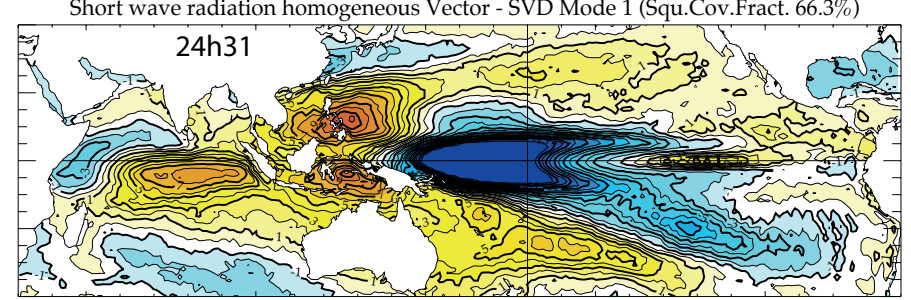

j) 24h31, latent heat flux / SST MCA

Latent heat flux homogeneous Vector - SVD Mode 1 (Squ.Cov.Fract. 55.8\%)

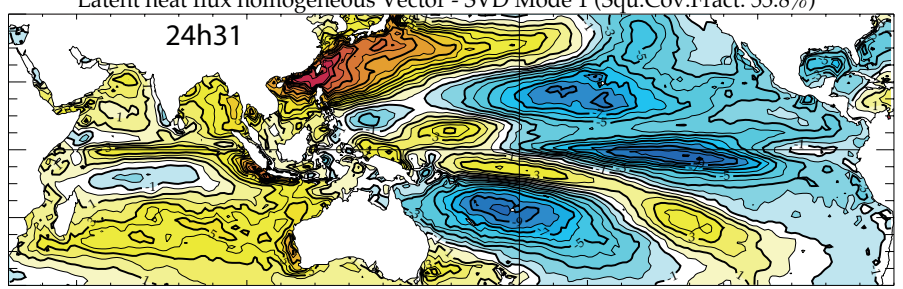

